\title{
Hotter and Drier Climate Made the Mediterranean Europe and Northern Africa Region a Shrubbier Landscape
}

\section{Wei Fang}

Pace University

Chuixiang Yi ( $\square$ cyi@qc.cuny.edu )

CUNY Queens College: Queens College https://orcid.org/0000-0001-8546-6157

\section{Deliang Chen}

University of Gothenburg: Goteborgs Universitet

\section{Peipei Xu}

Anhui Normal University

\section{George Hendrey}

CUNY Queens College: Queens College

Nir Krakauer

CUNY City College: The City College of New York

\section{Katherine Jensen}

CUNY City College: The City College of New York

\section{Shan Gao}

Chinese Academy of Sciences

Zihan Lin

Michigan State University

Gabriella Lam

Pace University

\section{Qin Zhang}

Dalian University of Technology

\section{Tao Zhou}

Beijing Normal University

\section{Research Article}

Keywords: LAl deficit, GPP deficit, climate drivers, legacy effect, landcover transition

Posted Date: February 19th, 2021

DOI: https://doi.org/10.21203/rs.3.rs-214050/v1 
License: (c) (i) This work is licensed under a Creative Commons Attribution 4.0 International License. Read Full License

Version of Record: A version of this preprint was published at Oecologia on October 13th, 2021. See the published version at https://doi.org/10.1007/s00442-021-05041-3. 
1 Hotter and Drier Climate Made the Mediterranean Europe and Northern Africa Region a

2 Shrubbier Landscape!

4 Running Title: Mediterranean Area has Become Shrubbier

5

6 Wei Fang ${ }^{1,2}$, Chuixiang $\mathrm{Yi}^{* 2,3}$, Deliang $\mathrm{Chen}^{4}$, Pei Xu ${ }^{2,5}$, George Hendrey ${ }^{2,3}$, Nir Krakauer ${ }^{3,6}$,

7 Katherine Jensen ${ }^{3,6}$, Shan Gao ${ }^{2,7}$, Zihan Lin $^{8}$, Gabriella Lam ${ }^{1}$, Qin Zhang ${ }^{2,9}$, Tao Zhou ${ }^{10}$

$9 \quad{ }^{1}$ Department of Biology, Pace University, New York, NY 10038, USA

$10{ }^{2}$ School of Earth and Environmental Sciences, Queens College, City University of New York,

11 Flushing, NY 11367, USA

$12{ }^{3}$ The Graduate Center, City University of New York, New York, NY 10016, USA

$13 \quad{ }^{4}$ Department of Earth Sciences, University of Gothenburg, 40530 Gothenburg, Sweden

$14{ }^{5}$ School of Geography and Tourism, Anhui Normal University, Wuhu 241002, China

$15{ }^{6}$ The City College of New York, City University of New York, New York, NY 10031, USA

$16{ }^{7}$ Institute of Tibetan Plateau Research, Chinese Academy of Sciences, Beijing 100101, China

$17{ }^{8}$ Center for Global Change and Earth Observations, Michigan State University, East Lansing,

18 Michigan 48823, USA

$19{ }^{9}$ Dalian University of Technology, Dalian 116024, China.

$20{ }^{10}$ Faculty of Geographical Science, Beijing Normal University, Beijing 100875, China

22 Corresponding author: chuixiang.yi@qc.cuny.edu

\footnotetext{
! Author Contributions: CY and WF conceived and formulated the idea. WF, KJ, ZL processed the satellite data, WF, SG performed statistical analysis, WF, DL, PX wrote the manuscript; other authors provided editorial advice.
} 
23 Abstract: A shift to warmer temperatures has left the Mediterranean Europe and Northern

24 Africa (MENA) region more vulnerable to drought and land degradation. We used LAI and GPP

25 deficit, the difference between actual and historical-maximum values, to describe vegetation

26 structural and functional dynamics and consequential landcover change in response to climate

27 variability during $2001-2019$ in the area $\left(20^{\circ} \mathrm{W}-45^{\circ} \mathrm{E}, 20^{\circ} \mathrm{N}-45^{\circ} \mathrm{N}\right)$. We found that (1) the

28 vegetation responses varied significantly among eight landcover types with the following ranked

29 importance: forests, savannas, a mosaic of cropland and natural vegetation (CNV), croplands,

30 permanent wetlands, urban land, grasslands, and shrublands, each with distinctive yet

31 overlapping signatures over the spectrums of the climate conditions considered. (2) Forests,

32 occupying the coolest and wettest niche of the MENA region, showed the strongest and most

33 dominating response to severe drought with a lag of 1-3 years and a legacy of 10 years. (3) The

34 total areas of savannas and CNV mosaics in MENA increased by $394,994 \mathrm{~km}^{2}$ and 404,592 $\mathrm{km}^{2}$

35 respectively while that of forests decreased by $33,091 \mathrm{~km}^{2}$ despite of the fertilizer effect of

36 elevated ambient $\mathrm{CO}_{2}$. Shrublands, occupying the hottest and driest niche of MENA, extended

37 by $287,134 \mathrm{~km}^{2}$ while grasslands and croplands retreated by $490,644 \mathrm{~km}^{2}$ and $225,263 \mathrm{~km}^{2}$. The

38 area of permanent wetlands increased by $49,192 \mathrm{~km}^{2}$, and that of urban land increased by 39,570

$39 \mathrm{~km}^{2}$. A net total of $57,649 \mathrm{~km}^{2}$ of barren land became vegetated over the years. With warmer

40 temperature and more extended period of drought, MENA has evolved towards a shrubbier

41 landscape.

42

43 Keywords: LAI deficit, GPP deficit, climate drivers, legacy effect, landcover transition

44

45 1. Introduction 
Landcover, especially vegetation dynamics over land, plays a critical role in atmospheric

47 processes and the water and carbon cycles globally (Foley, et al, 1996; Sitch et al, 2003; Assal et

48 al, 2016). An analysis of FLUXNET data revealed that the exchanges of carbon, water, and

49 energy between terrestrial ecosystems and the atmosphere are limited primarily by water

50 availability when the mean annual temperature is above a threshold of $16^{\circ} \mathrm{C}$ (Yi et al., 2010).

51 Climate records from the past six decades show that the annual mean temperature of a significant

52 part of the Mediterranean, Europe, and Northern Africa (MENA) region have shifted from below

53 to above this threshold of $16{ }^{\circ} \mathrm{C}$ (Yi et al., 2014; Allen et al., 2015; Huang et al., 2015). This

54 shift to higher temperatures has left the largely arid and semi-arid MENA region more vulnerable

55 to drought and land degradation (Somot et al., 2008; Segui et al., 2010; Friend, 2010; IPCC,

56 2013; Zhang et al., 2020). Studies have reported drought-induced forest impacts and diebacks in

57 the Mediterranean region (Allen et al., 2010; Carnicer et al., 2011; Peñuelas et al.,

58 2001; Martínez-Vilalta and Piñol, 2002; Matusick et al., 2013), as well as shifts in vegetation

59 composition (Jump and Peñuelas, 2005; Anderegg et al., 2013).

60 Climate-induced variability of vegetation in the MENA region is a matter of both

61 ecological and economic concern, as strong sensitivity to climate can result in rapid land use

62 change (Vanacker et al. 2005; Serra et al, 2008). Over longer time scales, relatively small shifts

63 in background climate can impact the distribution of ecosystems and potentially the viability of

64 agricultural and pastoral systems (Ciais et al., 2005; Vicente-Serrano et al., 2012). Interest in the

65 climate sensitivities of vegetation in semiarid regions is evident in the substantial body of

66 research devoted to characterizing the relationships between precipitation, soil type, land

67 management, and vegetation growth in these water-stressed regions (Zaitchik et al, 2007,

68 Vicente-Serrano et al, 2012). Previous studies have shown that, since 1948, warming climate has

69 moved the $16^{\circ} \mathrm{C}$ isotherm poleward, leading to a predicted northward shift of vegetation 
70 distribution of the Northern hemisphere (Yi et al, 2014). Vicente-Serrano et al (2012) also

71 showed a decline of the average vegetation cover in the semiarid Mediterranean environments

72 during 1984-2008.

At regional to continental scales, satellite observation offers a feasible and effective

74 approach for monitoring vegetation dynamics. One of the most common observations of

75 vegetation dynamics is based on the normalized difference vegetation index (NDVI). The NDVI,

76 computed as a normalized ratio of reflectance in the near-infrared and red portions of the

77 electromagnetic spectrum, provides a measure of chlorophyll abundance at the Earth's surface

78 and offers an indirect measure of energy absorption and vegetation density (Myneni et al., 1995;

79 Kerr et al., 2003).

A number of vegetation indices with direct ecological meanings are derived from NDVI

81 using additional algorithms and information. One of them is the leaf area index (LAI). LAI is a

82 fundamental parameter that reflects vegetation structure in the processes of fixing atmospheric

$83 \mathrm{CO} 2$ into organic matter. LAI is defined as the one-sided green leaf area per unit ground area in

84 broadleaf canopies and as half the total needle surface area per unit ground area in coniferous

85 canopies. Another widely used vegetation index is gross primary production (GPP), which is a

86 measure of the growth of the terrestrial vegetation that reflects vegetation function in the

87 processes of fixing atmospheric $\mathrm{CO} 2$ into organic matter. GPP correlates closely with LAI

88 where LAI is $\sim 4$ or less, suggesting that leaf area is a critical determinant of GPP in most of the

89 MENA region (Chapin III et al, 2011a).

90 This study takes advantage of interannual climatic variability during 2001-2019

91 (Sprintson et al., 2009; Fischer and Knutti, 2015) to characterize the climatic sensitivities of

92 vegetation in the MENA region. Time series data from the Moderate Imaging Spectrometer

93 (MODIS) are used to describe interannual patterns in vegetation. Data sources, processing steps, 
94 and methods are detailed below. We applied the "perfect deficit" approach (Yi et al., 2012) to

95 identify the primary climatic drivers of LAI variability over vegetation across the entire MENA

96 domain aggregated by landcover class.

97 We used both LAI deficit and GPP deficit as direct measures of climate and non-climate

98 stress on ecosystem structure and function experienced by the vegetation of the semiarid MENA

99 area. A focus is on climate stress expressed by a number of climate indices describing thermal

100 and water conditions and their combined effects. We attempt to establish empirical connections

101 of LAI deficit and GPP deficit with a few climate variables/indices (i.e. annual average

102 temperature (T), annual average precipitation ( $\mathrm{mm})$, Dryness Index, Temperature-Precipitation

103 (TP) Index, and Standardized Precipitation-Evapotranspiration Index (SPEI)). The aim is to

104 understand how landcover changes, especially vegetation structural and functional changes and

105 variabilities, respond to these climate variables: Specifically, we will find out which variable(s)

106 are the dominant driver(s) at the time scale of a decade. When vegetation types are considered

107 individually, we hypothesize that LAI deficit and GPP deficit of different vegetation types would

108 respond to climate variables differently, and the distribution of vegetation types may show a shift

109 over the years or may extend or shrink in response to climate change. The direction and intensity

110 of landcover shift over a short-term (i.e. after the 2002 severe drought) and a long-term (2001-

111 2018) will be further explored with landcover transition matrices. Such ecological assessment at

112 the temporal scale of decades is much needed for the strategic planning of resource management,

113 for optimizing vegetation productivity and ecosystem services.

114

\section{2. Materials and Methods}

\subsection{Climate and remote sensing data}


Remote sensing data such as MODIS LAI, GPP and landcover, and various climate

118 measures were collected for the MENA region, defined as the bounding box of $20^{\circ} \mathrm{N}-45^{\circ} \mathrm{N} \&$

$11920^{\circ} \mathrm{W}-45^{\circ} \mathrm{E}$. This is a box-shaped area around the Mediterranean Forests, Woodlands \& Scrub

120 biome defined by the World Wide Fund for Nature (WWF) in the MENA region (Fig.1).

\subsubsection{Remote sensing data}

Nineteen years (01-Jan-2001 - 31-Dec-2019) of global, 8-day composite MODIS LAI

124 (MODIS/006/MOD15A2H), GPP (MODIS/006/MOD17A2H), and yearly landcover data

125 (MODIS/006/MCD12Q1) at 500m resolution were obtained from the NASA Land Processes

126 Distributed Active Archive Center (LP DAAC), USGS/Earth Resources Observation and

127 Science (EROS) Center within Google Earth Engine. Annual landcover classification is defined

128 with the International Geosphere Biosphere Programme (IGBP) global vegetation classification

129 scheme. It describes the landcover properties derived from observations spanning a year of

130 Terra and Aqua MODIS data. The primary landcover scheme identifies 17 landcover classes

131 defined by IGBP, which includes 11 natural vegetation classes, 3 developed and mosaicked land

132 classes, and 3 non-vegetated land classes. The landcover types were further grouped into eight

133 categories of vegetated cover: forests (including class 1-5, evergreen needleleaf forest, evergreen

134 broadleaf forest, deciduous needleleaf forest, deciduous broadleaf forest and mixed forest),

135 shrublands (including class 6-7, closed shrublands and open shrublands), savannas (classes 8-9

136 woody savannas and savannas), grasslands (class 10), permanent wetlands (class 11), croplands

137 (class 12), urban and built-up (class 13) and crop+natural vegetation (CNV) mosaic (class 14).

138 Pixels with landcover changed over the years were coded white in the map (Fig. 1) and were

139 excluded for the no-landcover-change-based analyses along with the non-vegetated areas

140 (including snow and ice-class 15, barren land-class 16 and water-class 17). 


\subsubsection{Climate indices}

Two primary instrumental measures (temperature and precipitation) and three compound

144 climate indices (one with a linear function, one with an exponential function, and one being

145 standardized) were chosen for this study.

146 Monthly global surface air temperature (average air temperature at $2 \mathrm{~m}$ height) and

147 precipitation (monthly sum) data (01-Jan-2001 - 31-Dec-2019) in 0.25 degrees resolution were

148 provided by ECMWF/Copernicus Climate Change Service within Google Earth Engine. ERA5

149 is the fifth generation ECMWF atmospheric reanalysis of the global climate that combines model

150 data with observations from across the world into a globally complete and physically consistent

151 dataset.

152 To calculate dryness index, monthly average net radiation $\left(\mathrm{W} \mathrm{m}^{-2}\right)$ data (01-Jan-2001 -

153 31-Dec-2019) in 0.1 degrees resolution were collected from the FLDAS (Famine Early Warning

154 System Network (FEWS NET) Land Data Assimilation System) dataset (McNally et al, 2017)

155 provided by the NASA GES DISC at NASA Goddard Space Flight Center within Google Earth

156 Engine. This FLDAS dataset uses Noah version 3.6.1 surface model with CHIRPS-6 hourly

157 precipitation that has been downscaled using the NASA Land Surface Data Toolkit.

The radiation data were first resampled with the same projection system and resolution of

159 the temperature and precipitation data. Net radiation $\left(R_{n}\right)$ is defined as the difference between

160 net shortwave radiation and net longwave radiation.

161 The dryness index of Budyko was calculated by

162

$$
\text { Dryness }=\frac{R_{n}}{L P},
$$


163 where $R_{n}\left(\mathrm{MJ} \mathrm{m}^{-2} \mathrm{yr}^{-1}\right)$ and $P\left(\mathrm{~mm} \mathrm{yr}^{-1}\right)$ are respectively monthly mean net radiation and

164 precipitation for each grid cell and $L$ is a constant $2.5 \mathrm{MJ} \mathrm{kg}^{-1}$, the enthalpy of vaporization

165 (Budyko, 1961). Since temperature is often positively correlated with $R_{n}$, Dryness increases in

166 response to increasing $\mathrm{T}$ or decreasing $\mathrm{P}$. When there is no precipitation in a month, the dryness

167 index value could be infinitely large. Since on the global scale, the average net radiation was

168 between 98 and $112.6 \mathrm{~W} \mathrm{~m}^{-2}$ (Liang, 2017), the dryness index values (annual average of the

169 monthly values) were capped under 100 for later analysis.

170 Temperature-Precipitation (TP) Index was derived initially from a model of soil nitrogen

171 variations (Jenny, 1980) and further adapted to model vegetation responses to a changing climate

172 (Yi et al., 1996). It is calculated by

173

$$
T P=e^{0.08 T}\left(1 e^{0.005 P}\right)
$$

174 where $T\left({ }^{\circ} \mathrm{C}\right)$ and $P\left(\mathrm{~mm} \mathrm{yr}^{-1}\right)$ are annual mean temperature and precipitation for each grid cell

175 respectively (Yi et al., 1996). TP Index increases in response to decreasing T or increasing P.

177 balance, calculated by the standardization of water deficit $\mathrm{D}$, while

$$
D=P-P E T,
$$

179 where $\mathrm{P}\left(\mathrm{mm} \mathrm{yr}^{-1}\right)$ and PET $\left(\mathrm{mm} \mathrm{yr}^{-1}\right)$ are annual precipitation and potential evapotranspiration 180 for each grid cell respectively (Vicente-Serrano et al, 2010). The SPEI can measure drought 181 severity according to its intensity and duration. It can identify the onset and end of drought

182 episodes as well. The SPEI is a standardized variable, and it can therefore be compared with 183 other SPEI values over time and space. An SPEI of 0 indicates a value corresponding to $50 \%$ of 184 the cumulative probability of $\mathrm{D}$, according to a log-logistic distribution. 
(https://digital.csic.es/handle/10261/202305). The SPEI used in the analyses was at the 12-month temporal scale ending December of the previous year.

\subsection{Perfects, deficits and relative deficits}

Many large-scale vegetation and landcover studies are formulated as statistical analysis

192 of climatological anomalies. This study takes a vegetation-centric approach, focusing on the

193 differences of vegetation performance under optimal and suboptimal conditions.

Yi et al (2012) introduced a "perfect-deficit" approach for quantifying links between

195 climate extremes and variations in carbon storage. We apply this approach in developing a

196 climate stress indicator based on our MODIS LAI and GPP data in the MENA area for every 8-

197 day period throughout a year, then converted to monthly values. For each pixel, the "perfect"

198 LAI value of the month is defined as the maximum LAI value for this month over the 19 years, 199 and the "deficit" LAI value of the month for each year is defined as the difference between the 200 observed value from the "perfect" value of that month. Therefore, for the entire studied time 201 span (year 2001-2019) for the $i$ th month,

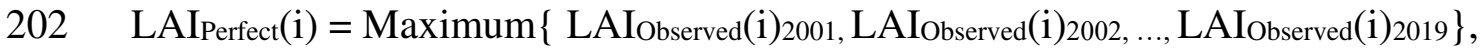

203 GPPPerfect(i) = Maximum $\{$ GPPobserved(i)2001, GPPobserved(i)2002, .., GPPobserved(i)2019 $\}$,

204 and for the $i$ th month of the $j$ th year,

$205 \quad$ LAIDeficit $_{(i, j)}=$ LAIPerfect $(\mathrm{i})-$ LAIObserved $(\mathrm{i}, \mathrm{j})$,

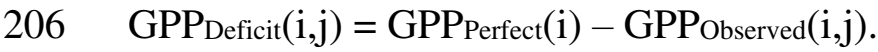

207 Essentially, we are looking at how the observed LAI for a given month under suboptimal climate 208 and ecological conditions departed from the highest value observed for that time of the year over 209 the 19-year period. The perfect value is presumed to correspond to the optimal growing 
210 conditions of climate, edaphic features, and other impinging ecological factors for that particular

211 area.

212 The monthly LAI or GPP deficit values were first averaged within each year to give us an

213 annual mean deficit for each pixel, then were averaged spatially (pixel by pixel) across each of

214 the landcover classes for each year.

215

$216 \quad 2.3$ Data Analyses

217 There were four sequential steps of data analyses as shown in Fig. 2. Step 1, eight

218 vegetated landcover types with no change over 18 years were extracted to conduct multiple

219 regression analyses; Step 2, regressions of vegetation structural (LAI deficit) and functional

220 (GPP deficit) responses over climate drivers (including temperature, precipitation, TP index,

221 dryness index, and SPEI) were conducted over all vegetated pixels and within each of 8

222 vegetation types; Step 3, results of 10 regression analyses and probability density function (PDF)

223 curves of 7 variables all pointed to the strong constraints within each vegetation type, which shed

224 new light on landcover changes over the years. Step 4, using the characteristic order along the

225 spectrums of climate variables and vegetation response variables, direction and intensity of

226 landcover change were quantified using time series and transition matrices.

227 All LAI, GPP and landcover data were retrieved within Google Earth Engine from

228 MODIS products (MOD15A2 and MOD17A2, MCD12Q1). All climate datasets (global surface

229 air temperature, precipitation, and net shortwave radiation data with temporal resolution of one

230 month) were resolved to a common projection at $0.25^{\circ}$ resolution. All annual LAI deficits,

231 annual GPP deficits, and all climate indices were calculated within Google Earth Engine using

232 JavaScript. Since we are looking for long-term large-scale patterns, all data were aggregated to

233 annual averages of eight landcover types. All processed spatial data were then exported to 
234 Geotiff files with WGS84 and 500m resolution for further statistical tests and graphing in R-

235 Studio (version 1.2.1335). All maps were made in ArcGIS Desktop 10.7.1.11595.

237 3. Results

$238 \quad 3.1$ Climate drivers

239 The first purpose of the study was to find the climate indices that the vegetation structure

240 indicator LAI and function indicator GPP responded to the most, and how those relationships

241 vary across different vegetation types. We found that overall LAI deficit was negatively

242 correlated with annual average temperature (Fig.3a1, Adjusted $\mathrm{R}^{2}=0.529, p<0.001$ ) and Dryness

243 (Fig.3a4, Adjusted $\mathrm{R}^{2}=0.588$ for linear and 0.770 for curvilinear relationship, $p<0.001$ ),

244 positively correlated with precipitation (Fig. 3a2, Adjusted $\mathrm{R}^{2}=0.613, p<0.001$ ) and TP Index

245 (Fig.3a4, Adjusted $\mathrm{R}^{2}=0.491, p<0.001$ ), and not correlated with SPEI (Fig.3a5, Adjusted

$246 \mathrm{R}^{2}=0.007, p=0.155$ ) (Table 1). When the vegetation was divided into eight categories, only

247 forest consistently showed a similar pattern to the overall vegetation structural responses while

248 shrubland showed an opposite trend or no trend.

249 Similarly, we found GPP deficit of overall vegetation was negatively correlated with

250 annual average temperature (Fig. 3b1, Adjusted $\mathrm{R}^{2}=0.553, p<0.001$ ) and dryness (Fig. 3b4,

251 Adjusted $\mathrm{R}^{2}=0.624$ for linear and 0.850 for curvilinear relationship, $p<0.001$ ), positively

252 correlated with accumulative precipitation (Fig. 3b2, Adjusted $\mathrm{R}^{2}=0.548, p<0.001$ ), TP Index

253 (Fig. 3b3, Adjusted $\mathrm{R}^{2}=0.509, p<0.001$ ), and weakly with SPEI (Fig. 3b5, Adjusted $\mathrm{R}^{2}=0.041$, $254 p=0.007)($ Table 1).

255 When divided into eight landcover categories: only forest showed an almost consistently

256 similar pattern to the overall vegetation structural responses while shrubland showed an opposite

257 trend or no trend. The only exception was in precipitation. Within each vegetation type, GPP 
258 deficit decreased when precipitation increased. In another word, more precipitation, less

259 reduction of GPP within each vegetation type as we would normally expect. The overall

260 correlation between GPP deficit and precipitation, however, is counter-intuitively positive. When

261 the timing of landcover change and PDF curves were closely examined in later part of this study,

262 it became clear that the overall pattern was more driven by intrinsic productivities of each

263 vegetation type rather than local responses to climate variables alone.

\section{2 Landcover-specific signatures over the spectrums of climate conditions}

Based on the probability density function (PDF) curves for both dependent variables (i.e.

267 vertical PDF graphs for LAI and GPP deficits) and independent variables (i.e. horizontal PDF

268 graphs for climate indices) (Fig 3), each vegetation cover demonstrated unique and sometimes

269 overlapping distribution signatures over the spectrums of structural and functional responses, and

270 climate conditions.

271 For example, forests had by far the highest LAI deficits $\left(11.28 \pm 1.12 \mathrm{~m}^{2} \mathrm{~m}^{-2}\right)$, followed by

272 savannas $\left(7.09 \pm 0.74 \mathrm{~m}^{2} \mathrm{~m}^{-2}\right), \mathrm{CNV}$ mosaic $\left(6.81 \pm 0.59 \mathrm{~m}^{2} \mathrm{~m}^{-2}\right)$, croplands $\left(6.75 \pm 0.50 \mathrm{~m}^{2} \mathrm{~m}^{-2}\right)$,

273 wetlands $\left(6.05 \pm 0.52 \mathrm{~m}^{2} \mathrm{~m}^{-2}\right)$, urban land $\left(3.94 \pm 0.31 \mathrm{~m}^{2} \mathrm{~m}^{-2}\right)$, grasslands $\left(3.30 \pm 0.38 \mathrm{~m}^{2} \mathrm{~m}^{-2}\right)$ and

274 shrublands $\left(1.48 \pm 0.21 \mathrm{~m}^{2} \mathrm{~m}^{-2}\right)$ in a descending order (Table 2). The LAI deficit of shrublands

275 was less than half of that of grasslands, which was the second lowest among all. Likewise,

276 forests had the highest GPP deficits, followed by the same descending order (Table 2). This

277 order reflected the differential responses, both structural and functional, to these climate

278 variables among these vegetation types, and their differential responses to climate stress.

279 When looking into the spectrums of climate conditions, stratification of landcover classes

280 by climate conditions is clearly evident in the data record. Forests occupied the coolest

$281\left(10.00 \pm 0.47^{\circ} \mathrm{C}\right)$ and wettest $(1102.31 \pm 87.31 \mathrm{~mm})$ niche while shrublands occurred in the hottest 
$282\left(17.46 \pm 0.32{ }^{\circ} \mathrm{C}\right)$ and driest $(342.24 \pm 49.24 \mathrm{~mm})$ area, polar opposite to forests. Each vegetation

283 landcover type is constrained within a limited range of climate conditions but each has a certain

284 level of overlapping with others. Within a constrained range of climate conditions, alternative

285 steady states (vegetation types) may exist.

2873.3 Landcover change over time

288 3.3.1 Remotely sensed areal change of landcover

289 According to the MODIS annual landcover product during 2001-2018, the total areas of

290 savannas and CNV mosaics in MENA increased by $394,994 \mathrm{~km}^{2}$ (5.26\% of savanna area in

$2912001)$ and $404,592 \mathrm{~km}^{2}$ (29.70\% of CNV area in 2001), with a significantly steady increasing

292 trend $\left(R^{2}=0.9295\right.$ and 0.9129 , respectively), while the area of forests decreased by $33,091 \mathrm{~km}^{2}$

293 (1.56\%) (Fig. 4a, 4b \& 4c) despite the fertilizer effect of elevated ambient $\mathrm{CO}_{2}$. Forest response

294 to elevated CO2 is conserved across a broad range of productivity (Norby, et al, 2005). What

295 was initially observed in the temperate FACE experiments may not be representative of other

296 regions (Hickler et al., 2008), and belowground response could be more continuous than

297 aboveground response to CO2 enrichment (Jackson et al, 2009) which cannot be detected by

298 satellite data.

299 More specifically, the area identified as forest in this analysis decreased by $41,401 \mathrm{~km}^{2}$

300 (a 2.92\% drop) over a period of 3 years following the drought/heat wave of 2002, and didn't

301 recover to the predrought level until 2014, 11 years after the drought. A second major drop

302 happened between 2016 and 2017, leaving an overall areal decline between 2001 and 2018.

303 Over the 18 years, shrublands, occupying the hottest and driest niche of MENA,

304 extended by $287,134 \mathrm{~km}^{2}(11.53 \%)$ while grasslands and croplands retreated by

$305490,644 \mathrm{~km}^{2}(4.62 \%)$ and 225,263 $\mathrm{km}^{2}$ (1.22\%) (Fig. 4d, 4e \&4f). Shrubs showed a 5- 
306 year increase after the 2002 drought and an overall increasing trend in shrublands (Fig.

307 4f), while grasses showed an initial 3-year increase after the 2002 drought then

308 continuous decline afterwards for 13 years (Fig. 4e). Croplands occupied the largest

309 area in $2003\left(18,582,372 \mathrm{~km}^{2}\right)$ both temporally across 18 years and spatially across 8

310 vegetation types, right after the 2002 drought, then declined afterwards with

311 fluctuations

312 The area of permanent wetlands increased by $49,192 \mathrm{~km}^{2}(24.88 \%)$, and that of urban

313 land increased by $39,570 \mathrm{~km}^{2}$ (2.90\%) (Fig. $\left.4 \mathrm{~g} \& 4 \mathrm{~h}\right)$.

314

315 3.3.2 Matrices of landcover change

316 To quantify the direction and intensity of change, we used the area of each vegetation

317 type that had changed to make transition matrices. A transition matrix could illustrate the

318 detailed vegetation transition during either a short-term period (i.e. during 2002-2003 right after

319 the 2002 heatwave/drought, Table 3a) or a long-term period (i.e. during 2001-2018, Table 3b, 320 Fig. 5).

321 In Table $3 a$ and $3 b$, the diagonal cell areas remained in the same vegetation types. The

322 upper right triangle portion indicates transitions to a less productive vegetation type, while the 323 lower left triangle indicates transitions to a more productive vegetation type, based on what we 324 have learned from PDF curves of LAI and GPP deficits.

325 During 2002-2003, 17,775 $\mathrm{km}^{2}$ of forested area became less productive and remote 326 sensing identified them as savannas. While a total of $22,680 \mathrm{~km}^{2}$ of barren land became 327 vegetated (turned into grassland and shrubland). As a result, a total of $52,986 \mathrm{~km}^{2}$ became less 328 productive based on the four categories with over $5,000 \mathrm{~km}^{2}$ (i.e. from forest to savanna, from 329 savanna to grassland, from cropland to grassland, and from grassland to shrubland) while a total 
330 of $56,814 \mathrm{~km}^{2}$ became more productive based the five categories listed in the lower triangle (i.e.

331 from grassland to savanna, from grassland to cropland, from shrubland to grassland, and from

332 barren land to either grassland or shrubland).

333 During 2001-2018, 55,948 $\mathrm{km}^{2}$ of forested area became less productive savannas (Fig.5,

334 visible in southern France and western Portugal) while $54,475 \mathrm{~km}^{2}$ of savannas had the reversed

335 transition, leaving a net loss of forests by a mere $1,473 \mathrm{~km}^{2}$. A total of $85,257 \mathrm{~km}^{2}$ of barren land

336 became vegetated (mostly turned into grassland and shrubland) and 27,609 $\mathrm{km}^{2}$ of vegetated

337 pixels became barren, leaving a net gain of $57,649 \mathrm{~km}^{2}$ of vegetated area from barren land

$338(0.913 \%)$. Such green-up is visible in parts of northern Algeria and Tunisia, eastern Iran,

339 northern Saudi Arabia and northern Egypt (Fig. 5). There was a total area of 413,922 $\mathrm{km}^{2}$ that

340 became more productive and $260,560 \mathrm{~km}^{2}$ became less productive (based only on categories of

341 transition with $20,000 \mathrm{~km}^{2}$ or more).

\section{4. Discussion}

344 The overall aim of the study was to use LAI and GPP deficits to identify and better

345 understand impacts of climate on landcover in the MENA region during 2001-2018. Specifically,

346 we would like to 1) determine critical climate drivers for internal variability of the landcover as a

347 whole and for several ecosystem types individually, 2) explore Landcover-specific signatures

348 over the spectrums of climate conditions, and 3) identify landcover changes over time and relate

349 these changes to climate changes (and other non-climatic drivers).

\subsection{Vegetation-centric approach of LAI and GPP deficits}

351 LAI and GPP deficits, the vegetation-centric approach, provide a different perspective 352 into the climate-vegetation interaction, contrast to the traditional climate anomaly approach. 
Through examining the responses of LAI deficit and GPP deficit of all vegetation types

354 combined and individually to various climate indices (including T, P, TP Index, Dryness and

355 SPEI), using univariate regression analyses, both LAI and GPP deficits proved to be effective

356 indicators of how ecosystem photosynthetic structures and functions respond to climate stress.

357 This study took this as a starting point to further explore the responses of the two deficits to

358 climatic conditions for the MENA region.

In general, regressions of LAI deficits and GPP deficits behaved very similarly, except to precipitation (Fig. 3 a $2 \&$ b2). Both Forest and overall LAI deficits $\left(\mathrm{m}^{2} \mathrm{~m}^{-2}\right)$ had a positive

361 correlation with annual precipitation $(\mathrm{mm})$, which was quite counter-intuitive. To understand 362 this, let's start with Fig. 3b2.

Within each vegetation type, GPP deficits $\left(\mathrm{kg} \mathrm{C} \mathrm{m}^{-2}\right)$ decreased when annual

364 precipitation $(\mathrm{mm})$ increased, which meant less GPP loss within the same year with more

365 precipitation. This is consistent with existing literature (Wu et al, 2011; Nielsen et al., 2015).

366 The overall regression of GPP deficits over precipitation, however, had a positive slope, which

367 was overwhelmingly dominated by intrinsic variation among different vegetation types (i.e.

368 forests generally have the highest GPP base, therefore its absolute increase in response to

369 increase of precipitation should be the highest).

370 Likely, as in Fig. 3a2, the overall regression of LAI deficits over precipitation had a

371 positive slope, with the same reason as for GPP deficits - they are tightly constrained within

372 each vegetation type. However, within forests, the regression slope was also positive. To

373 understand this pattern, we should also look at what has happened to the area (Fig. 4a and Table

374 3a). In 2002, the MENA region experienced a widespread severe drought. The total area of

375 forests decreased drastically from $2,102,011 \mathrm{~km}^{2}$ (in 2002) to 2,040,610 $\mathrm{km}^{2}$ (in 2003), and it

376 continued to decline for two more years (with 2005 having the smallest area of forests). It took 
another 10 years (2005-2014) for the area of forests to restore to the pre-drought level. In other

words, there were 3 years of lag and 10 years of legacy effects in terms of the distribution area of

379 forests. Similarly, forest area was at its highest in 2017, then declined drastically in 2018,

380 possibly due to another extreme event.

If we look at the time series of LAI deficits, the similar lag and legacy effects exist. The

382 decline of LAI happened in the following few years, therefore LAI was at its highest when

383 precipitation is at its lowest, or LAI deficit was the lowest when climate conditions (such as

384 precipitation) suddenly became less optimal. Therefore, we see this counter-intuitive positive

385 slope for regression of LAI deficits over annual precipitation.

\subsection{Five climate indices}

There are many climate indices available. For this study, we used two primary instrumental measures (temperature and precipitation) and three compound climate indices, each

390 presenting a different group of indices. Dryness index is expressed in a linear relationship

391 between net radiation and precipitation; TP index is expressed with an exponential formula, 392 containing temperature and precipitation; SPEI is a standardized index allowing flexibility of 393 temporal scales.

394 Since Dryness, TP index and SPEI all contain the information of precipitation and are not 395 independent from each other, multiple univariate regressions might be easier to interpret than a 396 single multivariate regression.

397 When response variables LAI deficit and GPP deficit were plotted against each of the 398 five climate indices, all except SPEI were tightly clustered within each vegetation type (Fig.3 399 and Table 2). Because SPEI is a standardized index, site specificity has probably been removed 400 during the calculation. On the other hand, these tightly distributed clusters may indicate strong 
resistance to transitions between vegetation types and alternative stable states caused by the

402 changing climate (Hirota et al, 2011; Chapin et al, 2011b). Although they currently seem to be

403 within the resilience ranges, further studies with finer spatial and temporal scales, and with finer

404 categorization of vegetation types and functional groups could tell a different story. Patterns

405 operating at finer scales will be different from what has been looked at (bigger scales), but this

406 may not necessarily lead to better understanding of the processes operating at coarser resolution

407 we have studied.

408

409

\subsection{Eight vegetation covers and their PDFs}

410 Despite their structural and functional responses to climate and ecological conditions,

411 most vegetation types are tightly constrained, representing steady states for specific

412 combinations of climate conditions and their immediate alternative steady states if strong enough

413 forces change them one way or another (Fig. 3a-h).

414 Opposite to patterns in the forests, shrubland LAI deficit was positively correlated with

415 Dryness. However, that does not necessarily mean if the area experienced prolonged directional

416 change related to temperature, water availability and solar radiation, a transition of vegetation

417 coverage between forests and shrubland could happen. When we looked deeply into the ranges

418 of annual average temperature $\left(10.00 \pm 0.47\right.$ vs $\left.17.46 \pm 0.32{ }^{\circ} \mathrm{C}\right)$, precipitation $(918.59 \pm 72.76$ vs

$419285.20 \pm 41.03 \mathrm{~mm})$, TP index $(0.51 \pm 0.03$ vs $0.19 \pm 0.01)$, Dryness $(2.37 \pm 0.54$ vs $20.77 \pm 3.95)$

420 and SPEI (-0.34 \pm 0.61 vs $-0.64 \pm 0.62)$ of forest and shrubland (Table 1), forest and shrubland are

421 experiencing very different local climate changes, thus led to polar opposite responses. The

422 results are consistent with the " $16^{\circ} \mathrm{C}$ threshold" prediction (Yi et al., 2010), which stated that the

423 exchanges of carbon, water, and energy between terrestrial ecosystems and the atmosphere are

424 limited primarily by water availability when mean annual temperature is above a threshold of 
$42516^{\circ} \mathrm{C}$ and by temperature when below $16^{\circ} \mathrm{C}$. Other studies also have looked into the changes of

426 landcover under the influence of climate change. For example, Macua et al. (2017) studied

427 factors affecting forest dynamics in the Iberian Peninsula from 1987 to 2012 based on Landsat

428 scenes, and found that the geographical transition from shrubland to forests is closely related to

429 higher soil moisture (Topographic Wetness Index-TWI) and lower winter solar radiation.

430 Meanwhile, strategies aiming at decreasing risk of decline and promoting resistance to abrupt

431 stress in the short-term may not enhance long-term resilience (Vilà-Cabrera, et al., 2018).

4334.4 Landcover changes and their concerning implications

434 Combining with transition maps, transition matrix is a powerful tool to specify the 435 direction and intensity of landscape changes over the region. Comparing short-term and long-

436 term transition matrix can also indicate how vegetation responds to extreme events (such as 2002 437 drought) immediately and in a long run.

438 Even though the percentage of vegetated area for forest (4.66\%) is far less than cropland 439 (41.19\%), grassland (23.88\%), savanna (17.38\%) and shrubland (5.95\%), the patterns of LAI 440 deficit of forest were always consistent with the LAI and GPP deficit of all vegetation, which

441 indicates the strong forest LAI response to climate and its dominating influence over the 442 response of the integrated vegetated landcover in our analysis. The MENA area was still

443 benefiting from the increase of ambient temperature and $\mathrm{CO}_{2}$ during 2001-2018 indicated in the 444 green-up of barren land and the gradual recovery of forested areas after the 2002 drought.

445 Overall, forests, cropland and grassland were more vulnerable to climate stress and had declined 446 over the past 18 years), while savanna and shrubland are more resilient and their distribution 447 expanded. 
One of most striking patterns was the increase of shrubs, both from upstream of cropland

449 and grasses and downstream of barren land. Based the areal changes of vegetation covers during 450 2001-2018 (partly in Table 3b), a total area of 38,938 $\mathrm{km}^{2}$ converted from grassland to shrubland 451 and $22,897 \mathrm{~km}^{2}$ from cropland to shrubland, while a total area of $37,853 \mathrm{~km}^{2}$ of shrubland

452 converted back to grassland and $14,163 \mathrm{~km}^{2}$ back to cropland. A total area of $52,376 \mathrm{~km}^{2}$

453 converted from barren land to shrubland, while $15,232 \mathrm{~km}^{2}$ of shrubland converted back to

454 barren land. There have been various reports on local shrubland die-back in the region (e.g.

455 Lloret et al., 2016 in south Spain), but the overall trend based on satellite data for entire MENA

456 region showing an increase. With higher temperature and more extended period of drought,

457 MENA is becoming less productive (with less forests and croplands) with more shrubby

458 vegetation covers, although a fraction of barren land (less than $1 \%$ ) became vegetated.

The two dominant vegetated landcovers in this area are cropland (41.19\%) and grassland

$460(23.88 \%)$ (Table 2). Areas of grassland and cropland fluctuated in opposite patterns over the

461 years (Fig. 4). This is likely due to the fact that the expansion of cropland was usually an

462 encroachment into grassland, while fallow croplands generally returned to grassland.

463 The average location and altitude of forest vegetation has not yet changed despite the 464 changes in temperature and dryness. On the other hand, the mean and median latitude of

465 cropland decreased over the last decade, likely due to human effort improving irrigation systems

466 for agriculture purposes. The mean latitude and median elevation of grassland also decreased

467 over the last decade, probably benefiting from the fertilization effect of elevated ambient $\mathrm{CO}_{2}$

468 concentration. This might have a tight association with the escalating incidence of wildfire near

469 arid and semiarid areas throughout the world, some of which have caused devastating losses.

470 Over the decade of 2001-2018 in MENA, the mean latitude $\left(\mathrm{R}^{2}=0.864, p<0.001\right)$ and

471 median latitude $\left(\mathrm{R}^{2}=0.513, p<0.05\right)$ of cropland both decreased significantly. Such a counter- 
472 intuitive change is probably due to huge effort of human intervention: establishing irrigation

473 systems and building dams for agriculture (United Nations, 1999; FAO, 2008).

474 The mean latitude $\left(\mathrm{R}^{2}=0.779, p<0.001\right)$ and median elevation $\left(\mathrm{R}^{2}=0.473, p<0.05\right)$ of 475 grassland also decreased significantly. Prior field manipulation experiments have shown that

476 elevated ambient $\mathrm{CO}_{2}$ concentration can stimulate the growth and accumulation of standing

477 biomass of grassland in semiarid areas, acting like a carbon fertilizer and a booster of water use

478 efficiency (Dijkstra et al, 2010). Grasses die back during the dry seasons, which naturally turn

479 into standing fuel, causing the increasing rate of wildfire and devastating loss. This has been 480 happening throughout the world, especially in Mediterranean ecoregions such as California, US

481 (Abatzoglou and Williams, 2016, Parks et al., 2017, Goss et al., 2020).

482 The area of permanent wetlands increased by $49,192 \mathrm{~km}^{2}(24.88 \%)$ most likely due to sea

483 level rise, and that of urban land increased by $39,570 \mathrm{~km}^{2}(2.90 \%)$ (Fig. $4 \mathrm{~g} \& 4 \mathrm{~h}$ ) due to human 484 land use.

487 - LAI and GPP deficits, the vegetation-centric approach, provided a different perspective into 488 the climate-vegetation interaction, contrast to the traditional climate anomaly approach.

489 - Vegetation responses varied among eight landcover types with distinctive yet overlapping 490 signatures over the spectrums of climate conditions considered, which shed a new light to the 491 direction of landcover change (alternatives of the steady state).

492 - Transition matrices (short-term and long-term) of landcover types could quantify the 493 direction and intensity of landcover changes after extreme events and over a period of time.

494 - The climate-vegetation interaction in the MENA region was leading to a shrubbier landscape. 495 


\section{Declarations}

498 Funding: This research was supported by NSF 81620108010 to WF, PSC-CUNY ENHC-48-33

499 and CUNY CIRG- 80209-08 22 to CY, and Federal Work-Study Undergraduate Research

500 Assistantship to GL.

501 Conflict of interest: The authors declare that they have no conflict of interest.

502 Ethical approval: This article does not contain any studies with human participants or animals

503 performed by any of the authors.

504 Consent to participate: All patients included in this study gave written informed consent to

505 participate in this research.

506 Consent for publication: All patients included in this research gave written informed consent to 507 publish the data and images contained within this case report.

508 Availability of data and code: The datasets and code used and/or analyzed during the current 509 study are available from the corresponding author on reasonable request. 
Allen, C. D., Breshears, D. D., \& McDowell, N. G. (2015) On underestimation of global vulnerability to tree mortality and forest die-off from hotter drought in the Anthropocene. Ecosphere, 6(8), art129. doi:https://doi.org/10.1890/ES15-00203.1

Allen, C. D., Macalady, A. K., Chenchouni, H., Bachelet, D., McDowell, N., Vennetier, M., .. . Cobb, N. (2010) A global overview of drought and heat-induced tree mortality reveals emerging climate change risks for forests. Forest Ecology and Management, 259(4), 660684. doi:10.1016/j.foreco.2009.09.001

Anderegg, W. R., Kane, J. M., \& Anderegg, L. D. (2013) Consequences of widespread tree mortality triggered by drought and temperature stress. Nature climate change, 3(1), 3036.

Assal, T. J., Anderson, P. J., \& Sibold, J. (2016) Spatial and temporal trends of drought effects in a heterogeneous semi-arid forest ecosystem. Forest Ecology and Management, 365, 137151. doi:https://doi.org/10.1016/j.foreco.2016.01.017

Berry, S. L., \& Roderick, M. L. (2002) Estimating mixtures of leaf functional types using continental-scale satellite and climatic data. Global Ecology and Biogeography, 11(1), 2339. doi:https://doi.org/10.1046/j.1466-822X.2002.00183.x

Budyko, M. I. (1961) The Heat Balance of the Earth's Surface. Soviet Geography, 2(4), 3-13. doi:10.1080/00385417.1961.10770761

Carnicer, J., Coll, M., Ninyerola, M., Pons, X., Sánchez, G., \& Peñuelas, J. (2011) Widespread crown condition decline, food web disruption, and amplified tree mortality with increased climate change-type drought. Proceedings of the National Academy of Sciences, 108(4), 1474-1478. doi:10.1073/pnas. 1010070108

Chapin, F., Matson, P., \& Mooney, H. (2002) Principles of Terrestrial Ecosystem Ecology. Paper presented at the Springer New York.

Chapin, F. S., Matson, P. A., \& Vitousek, P. M. (2011) Temporal Dynamics. In Principles of Terrestrial Ecosystem Ecology (pp. 339-367). New York, NY: Springer New York.

Chapin III, F. S., Matson, P.A., Vitousek, P. (2011) Principles of Terrestrial Ecosystem Ecology (2 ed.): Springer-Verlag New York.

Ciais, P., Reichstein, M., Viovy, N., Granier, A., Ogée, J., Allard, V., . . Valentini, R. (2005) Europe-wide reduction in primary productivity caused by the heat and drought in 2003. Nature, 437(7058), 529-533. doi:10.1038/nature03972

Dijkstra, F., Blumenthal, D., Morgan, J., LeCain, D., \& Follett, R. (2010) Elevated $\mathrm{CO}_{2}$ effects on semi-arid grassland plants in relation to water availability and competition. Functional Ecology, 24(5), 1152-1161. doi:10.1111/j.1365-2435.2010.01717.x

Foley, J., Prentice, I., Ramankutty, N., Levis, S., Pollard, D., Sitch, S., \& Haxeltine, A. (1996) Foley JA, Prentice IC, Ramankutty N, Levis S, Pollard D, Sitch S, Haxeltine A. 1996. An integrated biosphere model of land surface processes, terrestrial carbon balance, and vegetation dynamics. Global Biogeochem Cycles. Global Biogeochem. Cycles, 10, 603628. doi:10.1029/96GB02692

Food and Agriculture Organization of the United Nations. 2008. The near East and North Africa: growing demand, limited resources. FAO Newsroom. 
Friend, A. D. (2010) Terrestrial plant production and climate change. Journal of Experimental Botany, 61(5), 1293-1309. doi:10.1093/jxb/erq019

Goss, M., Swain, D. L., Abatzoglou, J. T., Sarhadi, A., Kolden, C. A., Williams, A. P., \& Diffenbaugh, N. S. (2020) Climate change is increasing the likelihood of extreme autumn wildfire conditions across California. Environmental Research Letters, 15(9), 094016. doi:10.1088/1748-9326/ab83a7

HICKLER, T., SMITH, B., PRENTICE, I. C., MJÖFORS, K., MILLER, P., ARNETH, A., \& SYKES, M. T. (2008) CO2 fertilization in temperate FACE experiments not representative of boreal and tropical forests. Global change biology, 14(7), 1531-1542. doi:https://doi.org/10.1111/j.1365-2486.2008.01598.x

Hirota, M., Holmgren, M., Van Nes, E. H., \& Scheffer, M. (2011) Global resilience of tropical forest and savanna to critical transitions. Science, 334(6053), 232-235. doi:10.1126/science. 1210657

Huang, K., Yi, C., Wu, D., Zhou, T., Zhao, X., Blanford, W. J., . . Li, Z. (2015) Tipping point of a conifer forest ecosystem under severe drought. Environmental Research Letters, 10(2), 024011. doi:10.1088/1748-9326/10/2/024011

Jackson, R. B., Cook, C. W., Pippen, J. S., \& Palmer, S. M. (2009) Increased belowground biomass and soil $\mathrm{CO} 2$ fluxes after a decade of carbon dioxide enrichment in a warmtemperate forest. Ecology, 90(12), 3352-3366. doi:10.1890/08-1609.1

Jenny, H. (1980) The soil resource. Origin and behavior. Vegetatio, 57(2), 102-102. doi:10.1007/BF00047304

Jump, A. S., \& Peñuelas, J. (2005) Running to stand still: adaptation and the response of plants to rapid climate change. Ecology letters, 8(9), 1010-1020.

Kerr, J. T., \& Ostrovsky, M. (2003) From space to species: ecological applications for remote sensing. Trends in ecology \& evolution, 18(6), 299-305.

Lloret, F., Enrique, G., Pérez-Ramos, I. M., Marañón, T., Saura-Mas, S., Díaz-Delgado, R., \& Villar, R. (2016) Climatic events inducing die-off in Mediterranean shrublands: are species' responses related to their functional traits? Oecologia, 180(4), 961-973.

Liang, S. (2017) Remote Sensing of Earth's Energy Budget: An Overview of Recent Progress. Comprehensive Remote Sensing Vol. 5: Earth's Energy Budget, 1-31.

Martínez-Vilalta, J., \& Piñol, J. (2002) Drought-induced mortality and hydraulic architecture in pine populations of the NE Iberian Peninsula. Forest Ecology and Management, 161(1-3), 247-256.

Matusick, G., Ruthrof, K. X., Brouwers, N. C., Dell, B., \& Hardy, G. S. J. (2013) Sudden forest canopy collapse corresponding with extreme drought and heat in a mediterranean-type eucalypt forest in southwestern Australia. European Journal of Forest Research, 132(3), 497-510.

McNally, A., Arsenault, K., Kumar, S., Shukla, S., Peterson, P., Wang, S., . . Verdin, J. P. (2017) A land data assimilation system for sub-Saharan Africa food and water security applications. Scientific data, 4(1), 1-19. 
Myneni, R., Maggion, S., Iaquinta, J., Privette, J., Gobron, N., Pinty, B., . . Williams, D. (1995) Optical remote sensing of vegetation: modeling, caveats, and algorithms. Remote sensing of environment, 51(1), 169-188.

Myneni, R. B., Hall, F. G., Sellers, P. J., \& Marshak, A. L. (1995) The interpretation of spectral vegetation indexes. IEEE Transactions on Geoscience and Remote Sensing, 33(2), 481486.

Nielsen, U. N., \& Ball, B. A. (2015) Impacts of altered precipitation regimes on soil communities and biogeochemistry in arid and semi-arid ecosystems. Glob Chang Biol, 21(4), 1407-1421. doi:10.1111/gcb.12789

Norby, R. J., Delucia, E. H., Gielen, B., Calfapietra, C., Giardina, C. P., King, J. S., . . Oren, R. (2005) Forest response to elevated $\mathrm{CO} 2$ is conserved across a broad range of productivity. Proc Natl Acad Sci U S A, 102(50), 18052-18056. doi:10.1073/pnas.0509478102

Parks, S. A., Holsinger, L. M., Miller, C., \& Parisien, M. A. (2018) Analog-based fire regime and vegetation shifts in mountainous regions of the western US. Ecography, 41(6), 910921.

Peñuelas, J., Lloret, F., \& Montoya, R. (2001) Severe drought effects on Mediterranean woody flora in Spain. Forest Science, 47(2), 214-218.

Seguí, P. Q., Ribes, A., Martin, E., Habets, F., \& Boé, J. (2010) Comparison of three downscaling methods in simulating the impact of climate change on the hydrology of Mediterranean basins. Journal of hydrology, 383(1-2), 111-124.

Serra, P., Pons, X., \& Saurí, D. (2008) Land-cover and land-use change in a Mediterranean landscape: a spatial analysis of driving forces integrating biophysical and human factors. Applied Geography, 28(3), 189-209.

Sitch, S., Smith, B., Prentice, I. C., Arneth, A., Bondeau, A., Cramer, W., . . Sykes, M. T. (2003) Evaluation of ecosystem dynamics, plant geography and terrestrial carbon cycling in the LPJ dynamic global vegetation model. Global change biology, 9(2), 161-185.

Somot, S., Sevault, F., Déqué, M., \& Crépon, M. (2008) 21st century climate change scenario for the Mediterranean using a coupled atmosphere-ocean regional climate model. Global and Planetary Change, 63(2-3), 112-126.

Sprintsin, M., Karnieli, A., Berliner, P., Rotenberg, E., Yakir, D., \& Cohen, S. (2009) Evaluating the performance of the MODIS Leaf Area Index (LAI) product over a Mediterranean dryland planted forest. International journal of Remote sensing, 30(19), 5061-5069.

Stocker, T. F., Qin, D., Plattner, G. K., Tignor, M. M., Allen, S. K., Boschung, J., ... \& Midgley, P. M. (2014). Climate Change 2013: The physical science basis. Contribution of working group I to the fifth assessment report of IPCC the intergovernmental panel on climate change.

United Nations. Economic Commission for Africa. Subregional Office for North Africa, (1999) Relevant water management and irrigation issues in North Africa. [Addis Ababa] @ UN. ECA.

Vanacker, V., Linderman, M., Lupo, F., Flasse, S., \& Lambin, E. (2005) Impact of short-term rainfall fluctuation on interannual land cover change in sub-Saharan Africa. Global Ecology and Biogeography, 14(2), 123-135. 
Vicente-Serrano, S. M., Beguería, S., \& López-Moreno, J. I. (2010) A multiscalar drought index sensitive to global warming: the standardized precipitation evapotranspiration index. Journal of climate, 23(7), 1696-1718.

Vicente-Serrano, S. M., Beguería, S., Lorenzo-Lacruz, J., Camarero, J. J., López-Moreno, J. I., Azorin-Molina, C., . . . Sanchez-Lorenzo, A. (2012) Performance of drought indices for ecological, agricultural, and hydrological applications. Earth Interactions, 16(10), 1-27.

Vicente-Serrano, S. M., Zouber, A., Lasanta, T., \& Pueyo, Y. (2012) Dryness is accelerating degradation of vulnerable shrublands in semiarid Mediterranean environments. Ecological Monographs, 82(4), 407-428.

Vidal-Macua, J. J., Ninyerola, M., Zabala, A., Domingo-Marimon, C., \& Pons, X. (2017) Factors affecting forest dynamics in the Iberian Peninsula from 1987 to 2012. The role of topography and drought. Forest Ecology and Management, 406, 290-306.

Vilà-Cabrera, A., Coll, L., Martínez-Vilalta, J., \& Retana, J. (2018) Forest management for adaptation to climate change in the Mediterranean basin: A synthesis of evidence. Forest Ecology and Management, 407, 16-22.

Wu, Z., Dijkstra, P., Koch, G. W., Peñuelas, J., \& Hungate, B. A. (2011) Responses of terrestrial ecosystems to temperature and precipitation change: a meta-analysis of experimental manipulation. Global change biology, 17(2), 927-942. doi:https://doi.org/10.1111/j.13652486.2010.02302.x

Yi, C., Kaiyu Lui, and Tiangjie Li,. (1996) Research on relations of soil zonal distributions with climate in the monsoon region of the eastern part of China. ACTA PEDOLOGICA SINICA, 32, 385-390.

Yi, C., Ricciuto, D., Li, R., Wolbeck, J., Xu, X., Nilsson, M., . . Arain, M. A. (2010) Climate control of terrestrial carbon exchange across biomes and continents. Environmental Research Letters, 5(3), 034007.

Yi, C., Rustic, G., Xu, X., Wang, J., Dookie, A., Wei, S., . . Nagy, Z. (2012) Climate extremes and grassland potential productivity. Environmental Research Letters, 7(3), 035703.

Yi, C., Wei, S., \& Hendrey, G. (2014) Warming climate extends dryness-controlled areas of terrestrial carbon sequestration. Scientific Reports, 4, 5472.

Zaitchik, B. F., Evans, J. P., Geerken, R. A., \& Smith, R. B. (2007) Climate and vegetation in the Middle East: Interannual variability and drought feedbacks. Journal of climate, 20(15), 3924-3941.

Zhang, P., Jeong, J. H., Yoon, J. H., Kim, H., Wang, S. S., Linderholm, H. W., Fang, K., Wu, X., Chen, D. (2020) Abrupt shift to hotter and drier climate over inner East Asia beyond the tipping point. Science, 370(6520), 1095-1099. doi:10.1126/science.abb3368 
671 Table 1 Regressions of annual LAI deficit and GPP deficit over climate drivers

$672(* * *$ indicates $\mathrm{p}<0.001 ; * *$ indicates $\mathrm{p}<0.01 ; *$ indicates $\mathrm{p}<0.05$; ns indicates $\mathrm{p}>0.05)$

673

674

\begin{tabular}{|c|c|c|c|c|c|c|c|}
\hline $\begin{array}{l}\text { Dependent } \\
\text { Variable (Y) } \\
\end{array}$ & $\begin{array}{l}\text { Independent } \\
\text { Variable }(\mathrm{X})\end{array}$ & $\begin{array}{l}\text { Adjusted Coefficient } \\
\text { of Determination }\left(\mathrm{R}^{2}\right)\end{array}$ & $\begin{array}{c}\text { Degree of freedom } \\
(\mathrm{df} 1, \mathrm{df} 2)\end{array}$ & $\begin{array}{l}\text { Significance } \\
\text { (p) }\end{array}$ & Intercept & Slope & \\
\hline \multirow[t]{5}{*}{ LAI Deficit } & Temperature & 0.53 & 1,150 & $<0.0001$ & 18.39 & -0.95 & $* *$ \\
\hline & Precipitation & 0.62 & 1,150 & $<0.0001$ & -1.73 & 0.01 & $\infty$ \\
\hline & TP Index & 0.50 & 1,150 & $<0.0001$ & -2.18 & 21.74 & 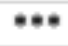 \\
\hline & Dryness Index & 0.59 & 1,150 & $<0.0001$ & 8.98 & -0.37 & $* \infty$ \\
\hline & SPEI & 0.01 & 1,150 & 0.15 & 6.12 & 0.64 & ns \\
\hline & & & & & & & \\
\hline \multirow[t]{5}{*}{ GPP Deficit } & Temperature & 0.55 & 1,151 & $<0.0001$ & 2925.10 & -129.56 & $\bullet \bullet$ \\
\hline & Precipitation & 0.55 & 1,151 & $<0.0001$ & 255.63 & 1.23 & $* *$ \\
\hline & TP Index & 0.51 & 1,151 & $<0.0001$ & 122.75 & 2952.20 & $* *$ \\
\hline & Dryness Index & 0.62 & 1,151 & $<0.0001$ & 1644.70 & -50.74 & $* \infty$ \\
\hline & SPEI & 0.04 & 1,151 & 0.01 & 1283.74 & 159.26 & $*$ \\
\hline
\end{tabular}

675

676 TP Index: Temperature-Precipitation Index;

677 SPEI: Standardized Precipitation-Evapotranspiration Index;

678 LAI: Leaf Area Index;

679 GPP: Gross Primary Productivity $\left(\mathrm{gCm}^{-2} \mathrm{yr}^{-1}\right)$

680 
681 Table 2 Vegetation responses, climate conditions and area for each landcover type

\begin{tabular}{|c|c|c|c|c|c|c|c|c|c|c|c|c|c|c|c|c|c|}
\hline & \multirow[t]{2}{*}{ Year (n) } & \multicolumn{2}{|c|}{ Forests } & \multicolumn{2}{|c|}{ Savannas } & \multicolumn{2}{|c|}{ CNVmosaic } & \multicolumn{2}{|c|}{ Grasslands } & \multicolumn{2}{|c|}{ Croplands } & \multicolumn{2}{|c|}{ Shrublands } & \multicolumn{2}{|c|}{ Wetlands } & \multicolumn{2}{|c|}{ Urban } \\
\hline & & Mean & Stdev & Mean & Stdev & Mean & Stdev & Mean & Stdev & Mean & Stdev & Mean & Stdev & Mean & Stdev & Mean & Stdev \\
\hline Average LAI Deficit & 19 & 11.28 & 1.12 & 7.09 & 0.74 & 6.81 & 0.59 & 3.30 & 0.38 & 6.75 & 0.50 & 1.48 & 0.21 & 6.05 & 0.52 & 3.94 & 0.31 \\
\hline GPP Defict $\left(\mathrm{gCm}^{-2} \mathrm{yr}^{-1}\right)$ & 19 & 1688.77 & 215.26 & 1489.04 & 199.60 & 1414.60 & 184.56 & 955.82 & 126.61 & 1413.75 & 167.39 & 509.14 & 66.47 & 1140.73 & 141.38 & 1082.17 & 130.98 \\
\hline Average Temperature $\left({ }^{\circ} \mathrm{C}\right)$ & 19 & 10.00 & 0.47 & 12.04 & 0.37 & 12.26 & 0.38 & 11.46 & 0.48 & 13.60 & 0.36 & 17.46 & 0.32 & 14.74 & 0.36 & 14.23 & 0.37 \\
\hline Precipitation (mm) & 19 & 1102.31 & 87.31 & 1008.09 & 88.36 & 896.59 & 82.67 & 748.08 & 49.67 & 643.01 & 50.51 & 342.24 & 49.24 & 736.53 & 66.18 & 736.76 & 61.23 \\
\hline TP Index & 19 & 0.51 & 0.03 & 0.41 & 0.02 & 0.39 & 0.02 & 0.45 & 0.03 & 0.35 & 0.02 & 0.19 & 0.01 & 0.31 & 0.01 & 0.34 & 0.02 \\
\hline Dryness Index & 19 & 2.37 & 0.54 & 4.68 & 0.88 & 2.11 & 0.34 & 11.87 & 2.05 & 9.54 & 1.11 & 20.77 & 3.95 & 9.17 & 1.69 & 7.75 & 1.06 \\
\hline SPEI & 19 & -0.34 & 0.61 & -0.45 & 0.52 & -0.42 & 0.60 & -0.31 & 0.47 & -0.47 & 0.42 & -0.64 & 0.62 & -0.49 & 0.49 & -0.51 & 0.41 \\
\hline Area $\left(100,000 \mathrm{~km}^{-2}\right)$ & 18 & 20.72 & 0.37 & 77.21 & 1.21 & 14.83 & 1.55 & 106.04 & 2.03 & 182.91 & 1.51 & 26.42 & 0.78 & 2.19 & 0.18 & 13.80 & 0.12 \\
\hline
\end{tabular}

683 LAI: Leaf Area Index;

684 GPP: Gross Primary Productivity $\left(\mathrm{gCm}^{-2} \mathrm{yr}^{-1}\right)$

685 TP Index: Temperature-Precipitation Index;

686 SPEI: Standardized Precipitation-Evapotranspiration Index;

687 
688 Table 3a Area $\left(\mathrm{km}^{2}\right)$ of vegetation type changed from 2002 (in rows) to 2003 (in columns)

689 (Note: only categories with more than $5,000 \mathrm{~km}^{2}$ are listed)

\begin{tabular}{|c|c|c|c|c|c|c|c|c|c|c|}
\hline $2002 \backslash 2003$ & Forest & Savanna & CNVmosaic & Cropland & Wetland & Urban & Grassland & Shrubland & Barren & Water \\
\hline Forest & 539687 & 17775 & & & & & & & & \\
\hline Savanna & (3854) & 845142 & & & & & 17186 & & & \\
\hline CNVmosaic & & & 89324 & & & & & & & \\
\hline Cropland & & & & 1518885 & & & 10727 & & & \\
\hline Wetland & & & & & 16949 & & & & & \\
\hline Urban & & & & & & 104781 & & & & \\
\hline Grassland & & 9834 & & 15729 & & & 1025717 & 7298 & & \\
\hline Shrubland & & & & & & & 8570 & 343054 & & \\
\hline Barren & & & & & & & 9879 & 12801 & 6367401 & \\
\hline Water & & & & & & & & & & 11527805 \\
\hline
\end{tabular}

691

692 Table 3b Area $\left(\mathrm{km}^{2}\right)$ of vegetation type changed from 2001 (in rows) to 2018 (in columns)

693 (Note: only categories with more $20,000 \mathrm{~km}^{2}$ are listed)

\begin{tabular}{|c|c|c|c|c|c|c|c|c|c|c|}
\hline $2001 \backslash 2018$ & Forest & Savanna & CNVmosaic & Cropland & Wetland & Urban & Grassland & Shrubland & Barren & Water \\
\hline Forest & 500508 & 55948 & & & & & & & & \\
\hline Savanna & 54475 & 716599 & 21938 & & & & 57586 & & & \\
\hline CNVmosaic & & & 71082 & & & & & & & \\
\hline Cropland & & 22846 & 29875 & 1390808 & & & 63253 & 22897 & & \\
\hline Wetland & & & & & 14708 & & & & & \\
\hline Urban & & & & & & 104735 & & & & \\
\hline Grassland & & 106902 & & 77943 & & & 814238 & 38938 & & \\
\hline Shrubland & & & & & & & 37853 & 280748 & & \\
\hline Barren & & & & & & & 31652 & 52376 & 6309837 & \\
\hline Water & & & & & & & & & & 11525705 \\
\hline
\end{tabular}

695 
Figure Legends:

697 Figure 1 A map of vegetated areas with no change of landcover types during 2001-2018 (500m

698 resolution) in Mediterranean Europe and North Africa (MENA, $20^{\circ} \mathrm{W}-45^{\circ} \mathrm{E} \& 20^{\circ} \mathrm{N}-45^{\circ} \mathrm{N}$ ).

699 Pixels that experienced landcover change were in white color. Annual landcover classification is

700 defined by the MODIS Landcover CMG (MCD12Q1) product's International Geosphere

701 Biosphere Programme (IGBP) global vegetation classification scheme (https://

702 lpdaac.usgs.gov/products/modis_products_table/mcd12c1). The primary landcover scheme

703 identifies 17 classes, and were grouped into 8 categories: forests (class 1-5), shrubland (class 6-

704 7), savannas (class 8-9), grasslands (class 10), permanent wetlands (class 11), croplands (class

705 12), urban and build-up (class 13) and crop+natural vegetation mosaic (class 14). The non-

706 vegetated areas (water and barren land) were excluded from relevant analyses.

707 Figure 2 Conceptual workflow of this study. Step 1, eight vegetated landcover types with no

708 change over 18 years were extracted to conduct multiple regression analyses; Step 2, regressions

709 of vegetation structural (LAI deficit) and functional (GPP deficit) responses over climate drivers

710 (including temperature $\left({ }^{\circ} \mathrm{C}, \mathrm{T}\right)$, precipitation $(\mathrm{mm}, \mathrm{P}), \mathrm{TP}$ index, Dryness index, SPEI

711 (Standardized Precipitation Evapotranspiration Index)) were conducted over all vegetated pixels

712 and within each vegetation type; Step 3, 10 regression analyses and probability density function

713 (PDF) curves of 7 variables sheding new light on future landcover changes. Step 4, direction and

714 intensity of landcover change were quantified using time series and transition matrices.

715 Figure 3 Regressions of vegetation structural (LAI deficit) and functional (GPP deficit)

716 responses over climate drivers (i.e. annual average temperature $\left({ }^{\circ} \mathrm{C}, \mathrm{T}\right)$, accumulative

717 precipitation (mm, P), Temperature-Precipitation (TP) index, Dryness index, SPEI (Standardized

718 Precipitation Evapotranspiration Index)) for all vegetated pixels (black lines, solid if $p<0.01$,

719 dotted if $p>0.05$ ) and within each of 8 vegetation types (color coded with $95 \%$ confidence

720 intervals in gray); For each panel, probability density function (PDF) curves were plotted with

721 the same scheme of color code, horizontal on the top for the climate variables (T, P, TP index,

722 Dryness or SPEI) and vertical on the right for the response variables (LAI or GPP deficit).

723 Figure 4 Total area $\left(\mathrm{km}^{2}\right)$ of eight vegetation types over the period of Jan. 1, 2001-Dec. 31,

7242018 in Mediterranean Europe and North Africa (MENA, $20^{\circ} \mathrm{W}-45^{\circ} \mathrm{E} \& 20^{\circ} \mathrm{N}-45^{\circ} \mathrm{N}$ ).

725 Figure 5 A map of vegetated areas with changes of landcover types during 2001-2018 (500m

726 resolution) in Mediterranean Europe and North Africa (MENA, $20^{\circ} \mathrm{W}-45^{\circ} \mathrm{E} \& 20^{\circ} \mathrm{N}-45^{\circ} \mathrm{N}$ ). 


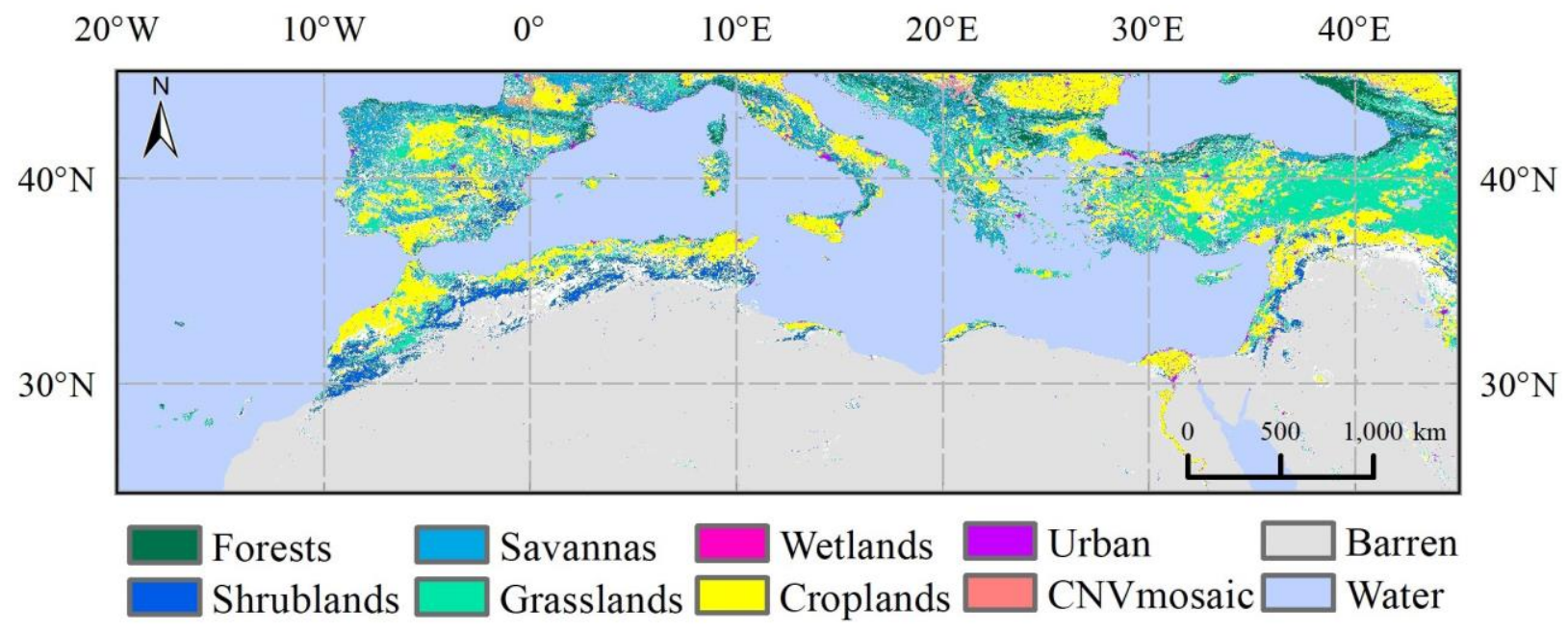

\section{$728 \quad$ Figure 1}

729 


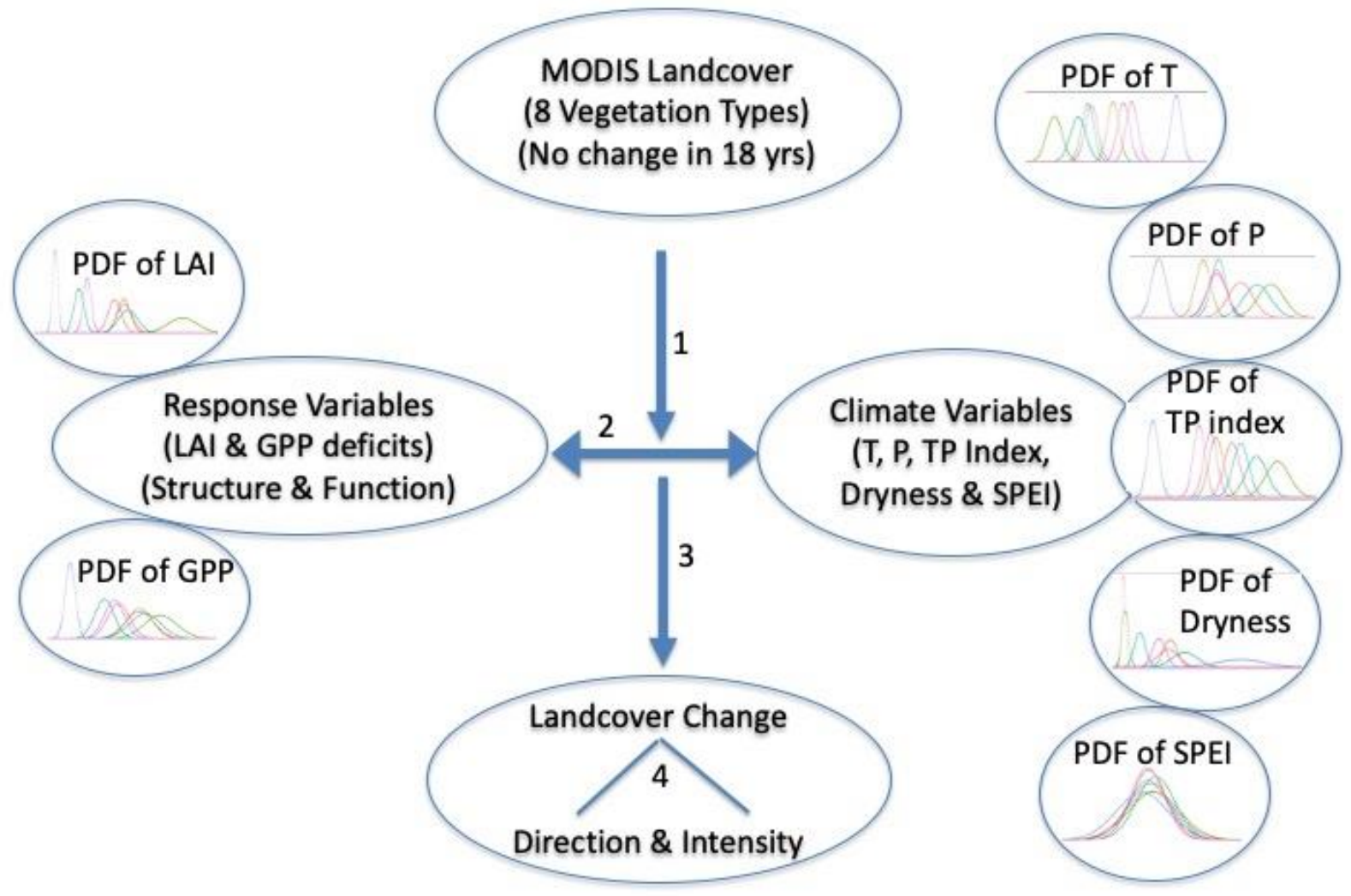

732 Figure 2

733 
734
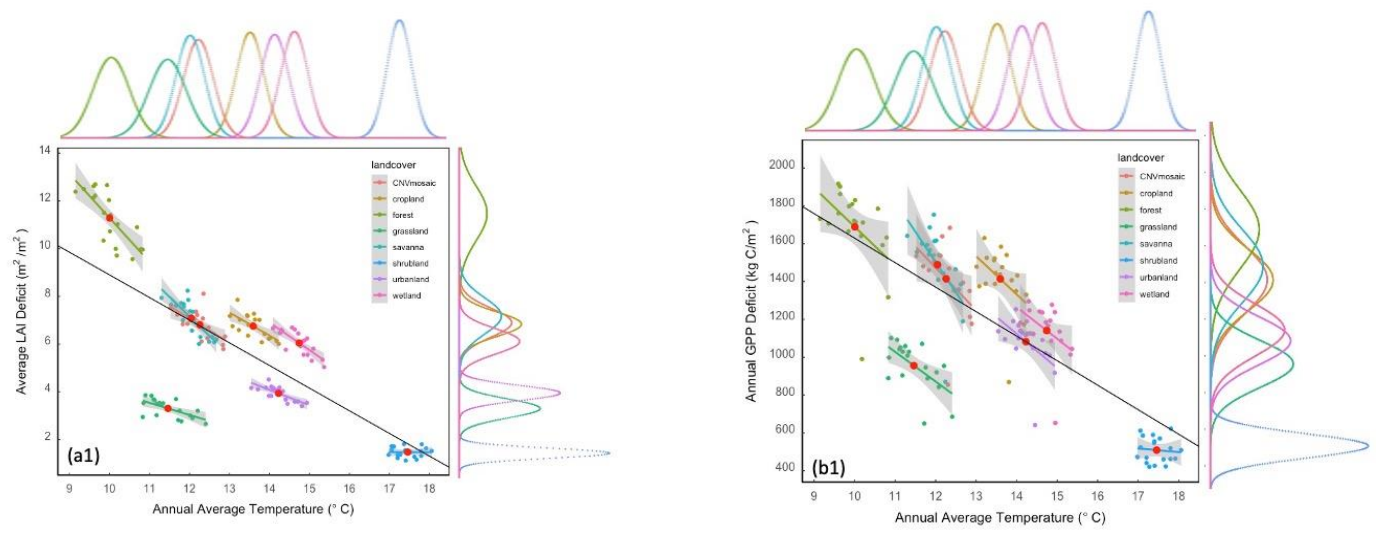

735

Fig. 3 a1

Fig. 3 b1
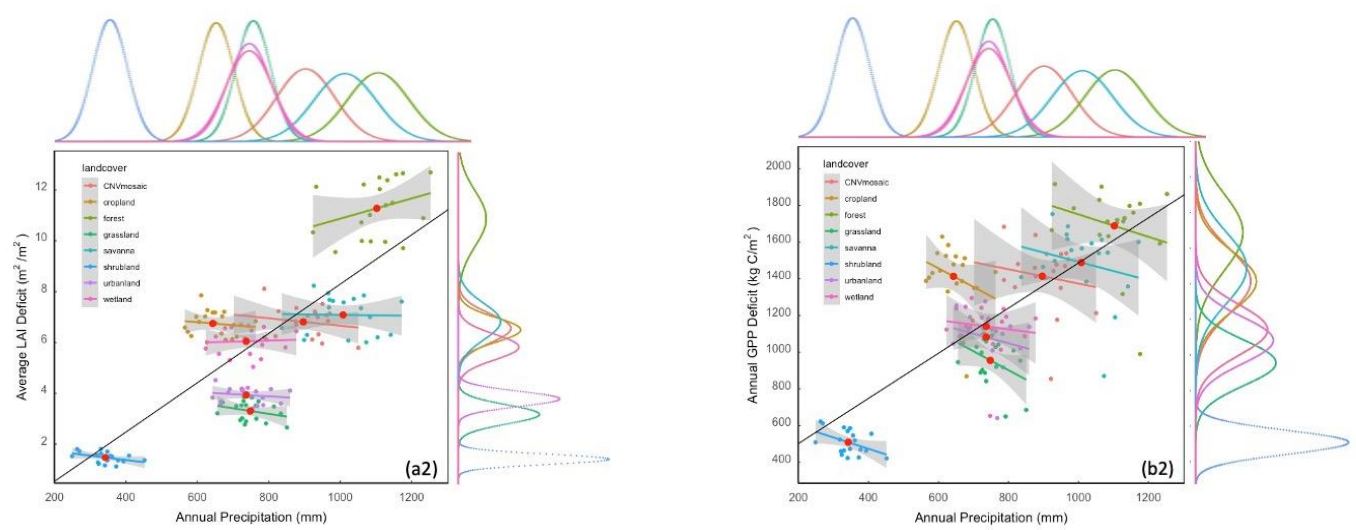

736

737

Fig. 3 a2

Fig. 3 b2

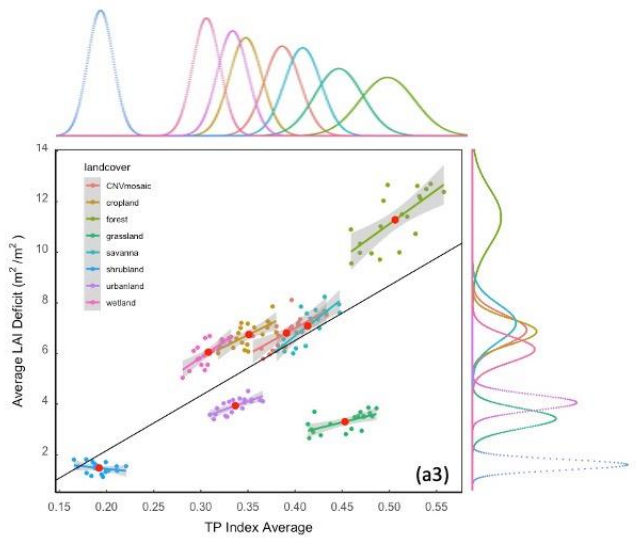

738

Fig. 3 a 3

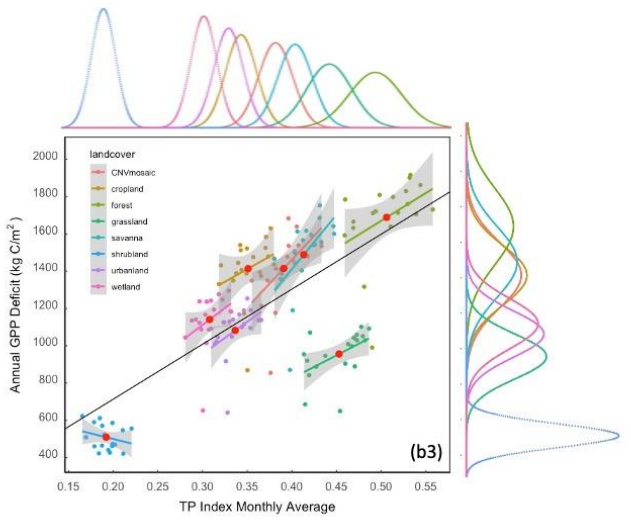

739

Fig. 3 b3 

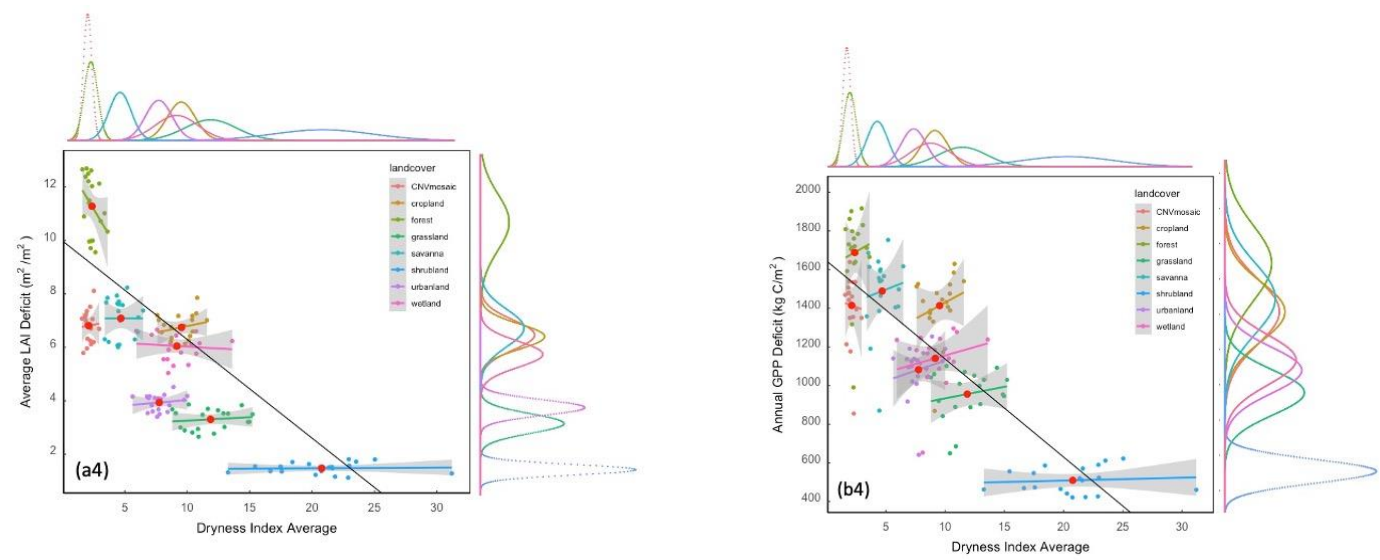

741

Fig. 3 a4

Fig. 3 b4

742
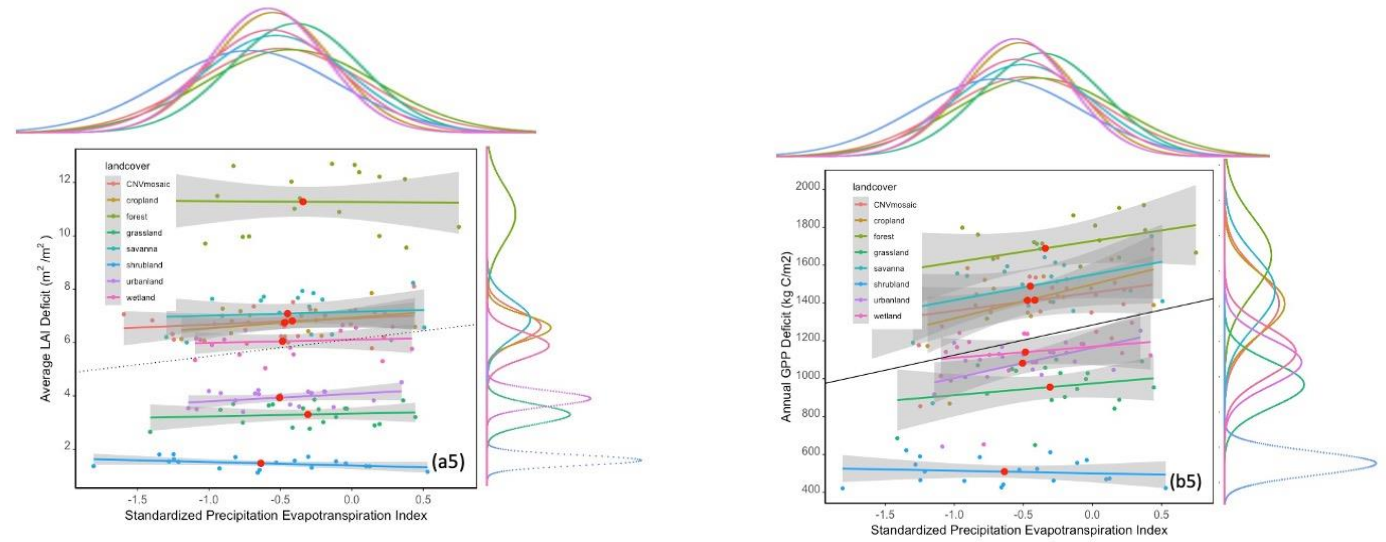

743

744

Fig. 3 a5

Fig. 3 b5 

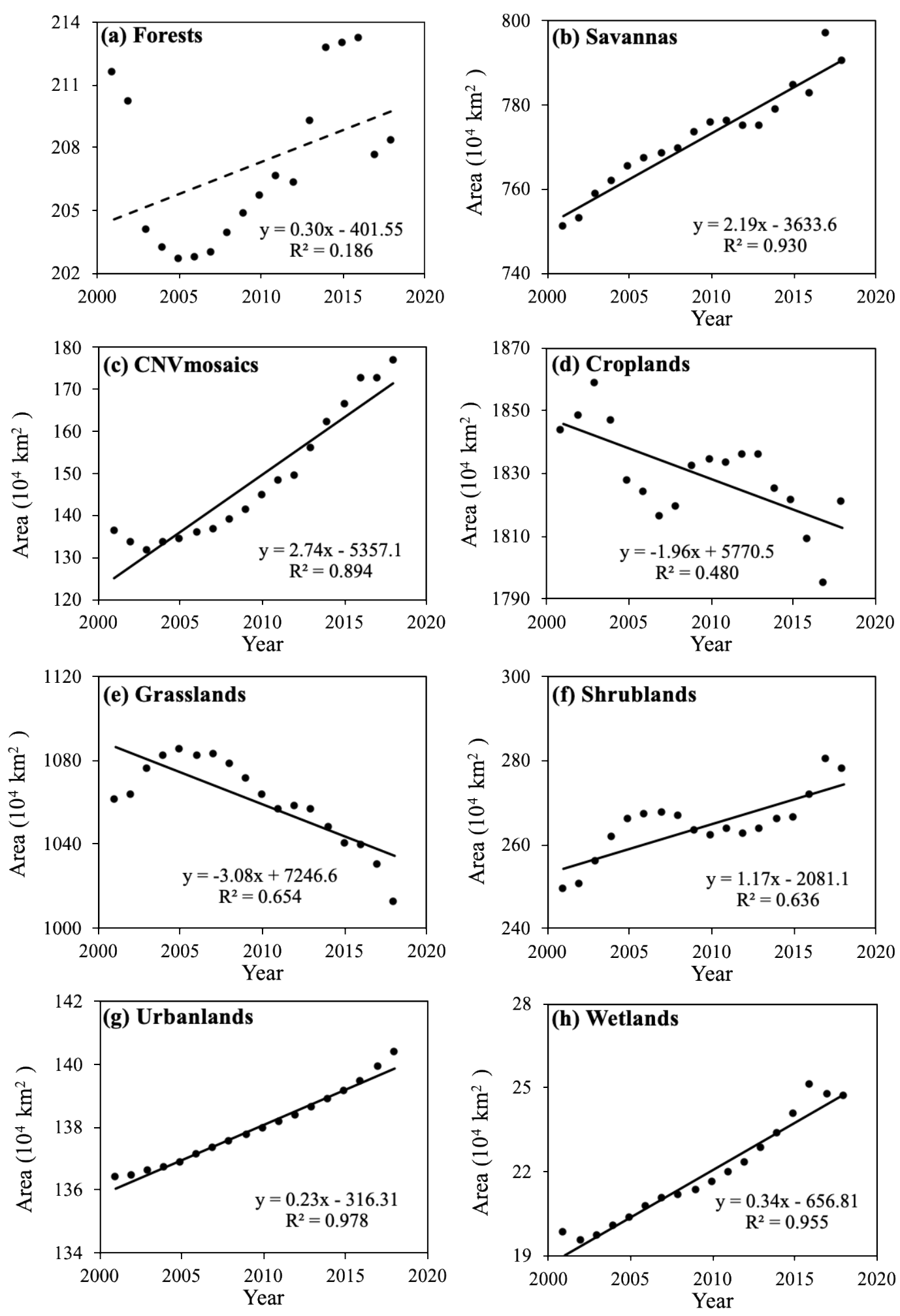

$746 \quad$ Fig. 4 


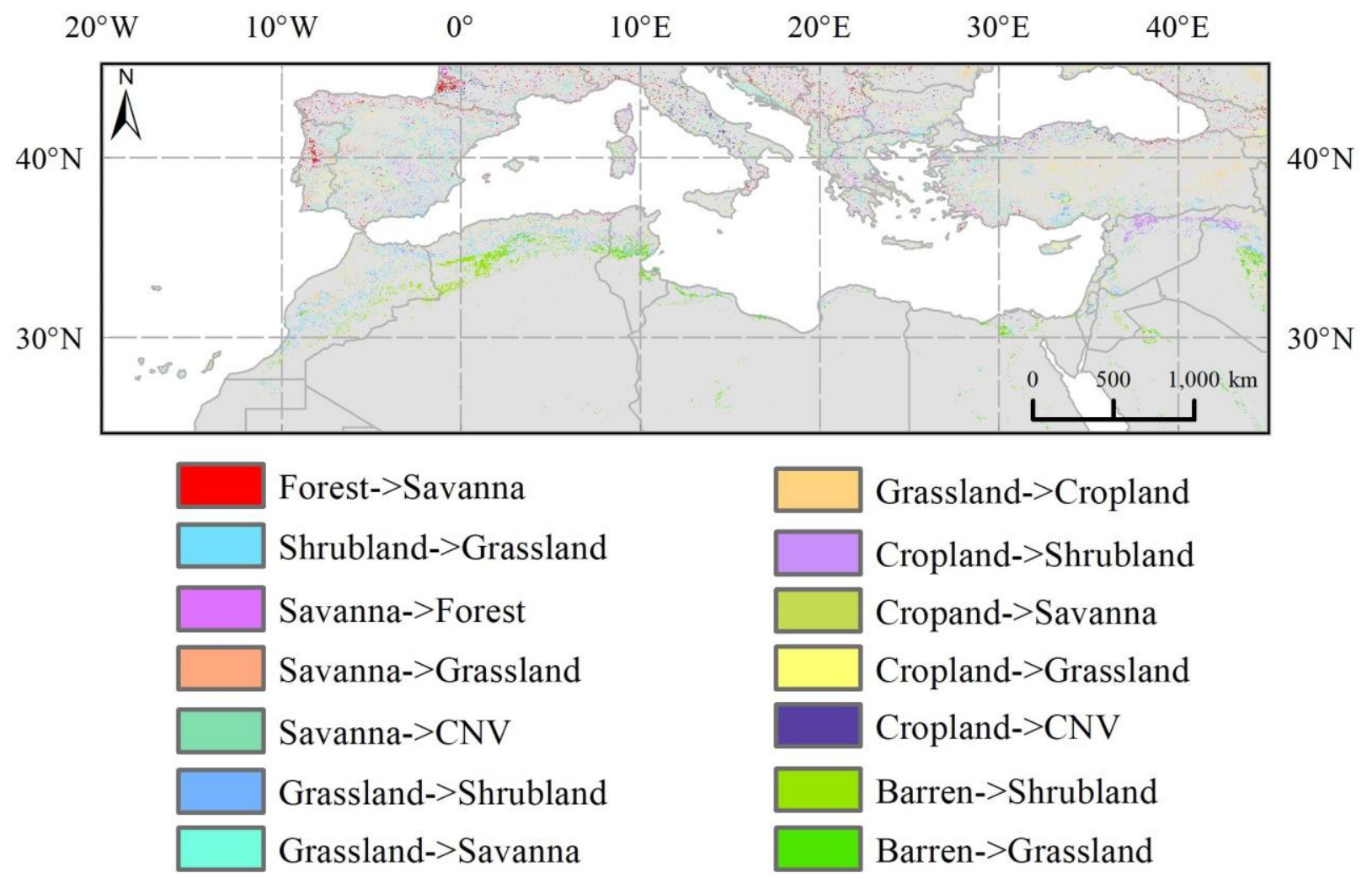

$750 \quad$ Figure 5 


\section{Figures}

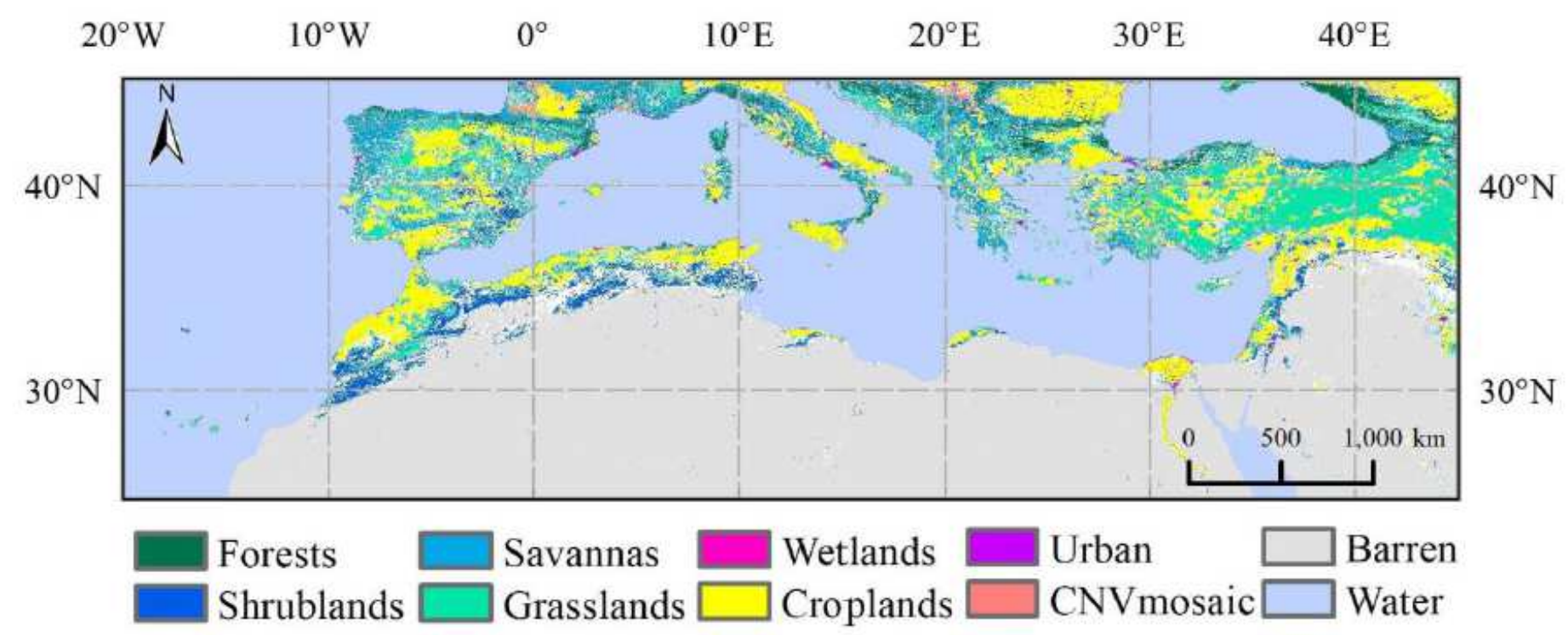

\section{Figure 1}

A map of vegetated areas with no change of landcover types during 2001-2018 (500m resolution) in Mediterranean Europe and North Africa (MENA, $20^{\circ} \mathrm{W}-45^{\circ} \mathrm{E} \& 20^{\circ} \mathrm{N}-45^{\circ} \mathrm{N}$ ). Pixels that experienced landcover change were in white color. Annual landcover classification is defined by the MODIS Landcover CMG (MCD12Q1) product's International Geosphere Biosphere Programme (IGBP) global vegetation classification scheme (https:// Ipdaac.usgs.gov/products/modis_products_table/mcd12c1). The primary landcover scheme identifies 17 classes, and were grouped into 8 categories: forests (class 1-5), shrubland (class 6-7), savannas (class 8-9), grasslands (class 10), permanent wetlands (class 11), croplands (class 12), urban and build-up (class 13) and crop+natural vegetation mosaic (class 14). The non- vegetated areas (water and barren land) were excluded from relevant analyses. 


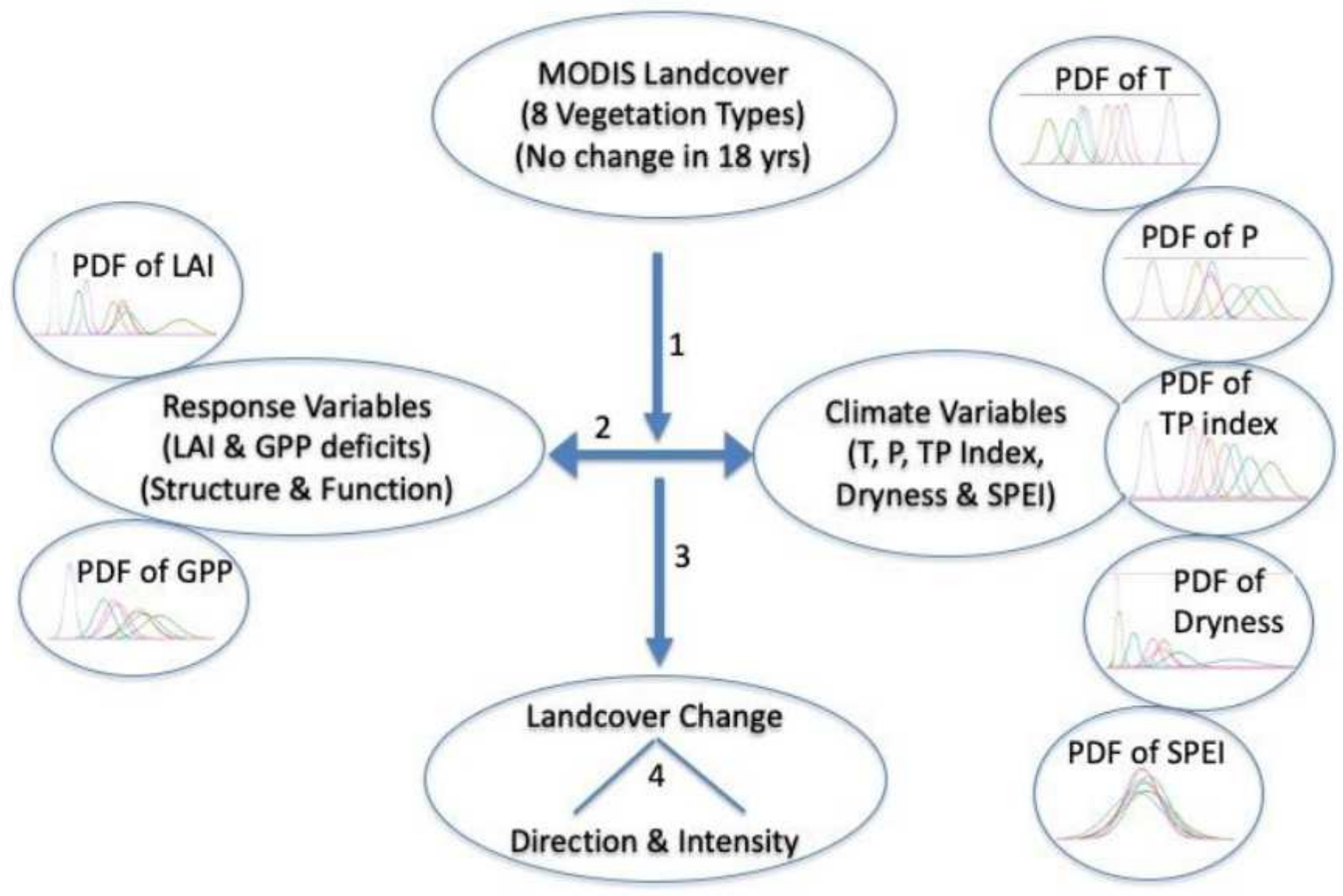

Figure 2

Conceptual workflow of this study. Step 1, eight vegetated landcover types with no change over 18 years were extracted to conduct multiple regression analyses; Step 2, regressions of vegetation structural (LAI deficit) and functional (GPP deficit) responses over climate drivers (including temperature $\left({ }^{\circ} \mathrm{C}, \mathrm{T}\right)$, precipitation (mm, P), TP index, Dryness index, SPEI (Standardized Precipitation Evapotranspiration Index)) were conducted over all vegetated pixels and within each vegetation type; Step 3, 10 regression analyses and probability density function (PDF) curves of 7 variables sheding new light on future landcover changes. Step 4, direction and intensity of landcover change were quantified using time series and transition matrices. 


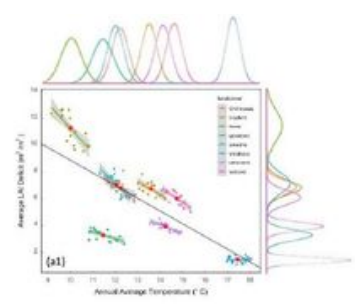

Fig.3 al

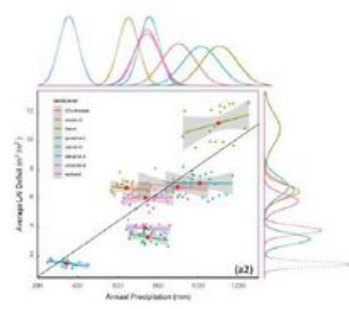

Fig. 3 a2

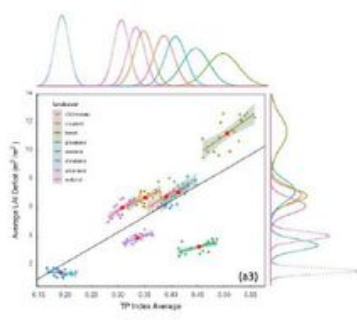

Fig. 3 a3

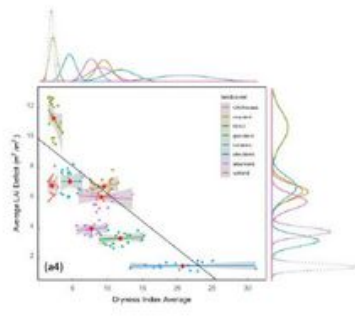

Fig.3 a4

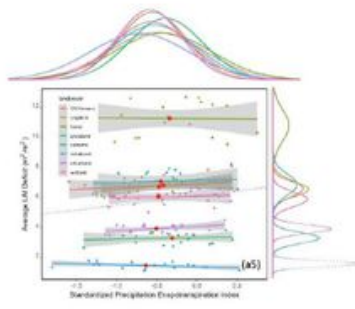

Fig.3 a5

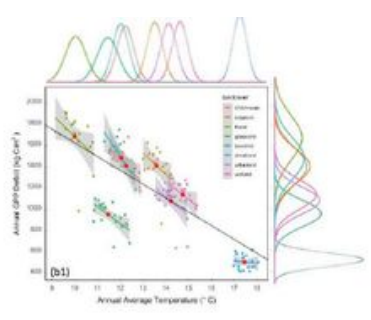

Fig.3 bl

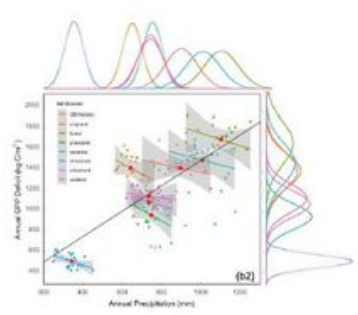

Fig. 3 b2

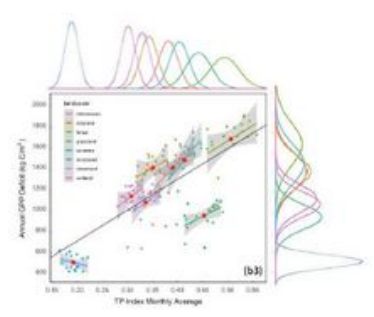

Fig. 3 b3

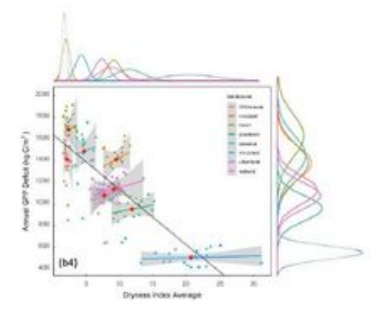

Fig.3 b4

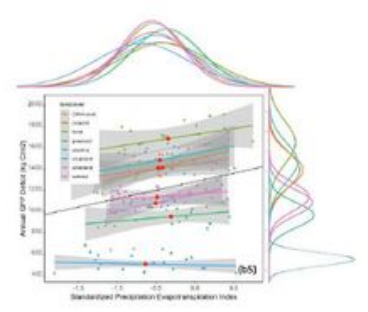

Fig. 3 b5

\section{Figure 3}

Regressions of vegetation structural (LAI deficit) and functional (GPP deficit) responses over climate drivers (i.e. annual average temperature $\left({ }^{\circ} \mathrm{C}, \mathrm{T}\right)$, accumulative precipitation $(\mathrm{mm}, \mathrm{P})$, TemperaturePrecipitation (TP) index, Dryness index, SPEI (Standardized Precipitation Evapotranspiration Index)) for all vegetated pixels (black lines, solid if $p<0.01$, dotted if $p>0.05$ ) and within each of 8 vegetation types (color coded with 95\% confidence intervals in gray); For each panel, probability density function (PDF) 
curves were plotted with the same scheme of color code, horizontal on the top for the climate variables ( $T$, P, TP index, Dryness or SPEI) and vertical on the right for the response variables (LAI or GPP deficit).
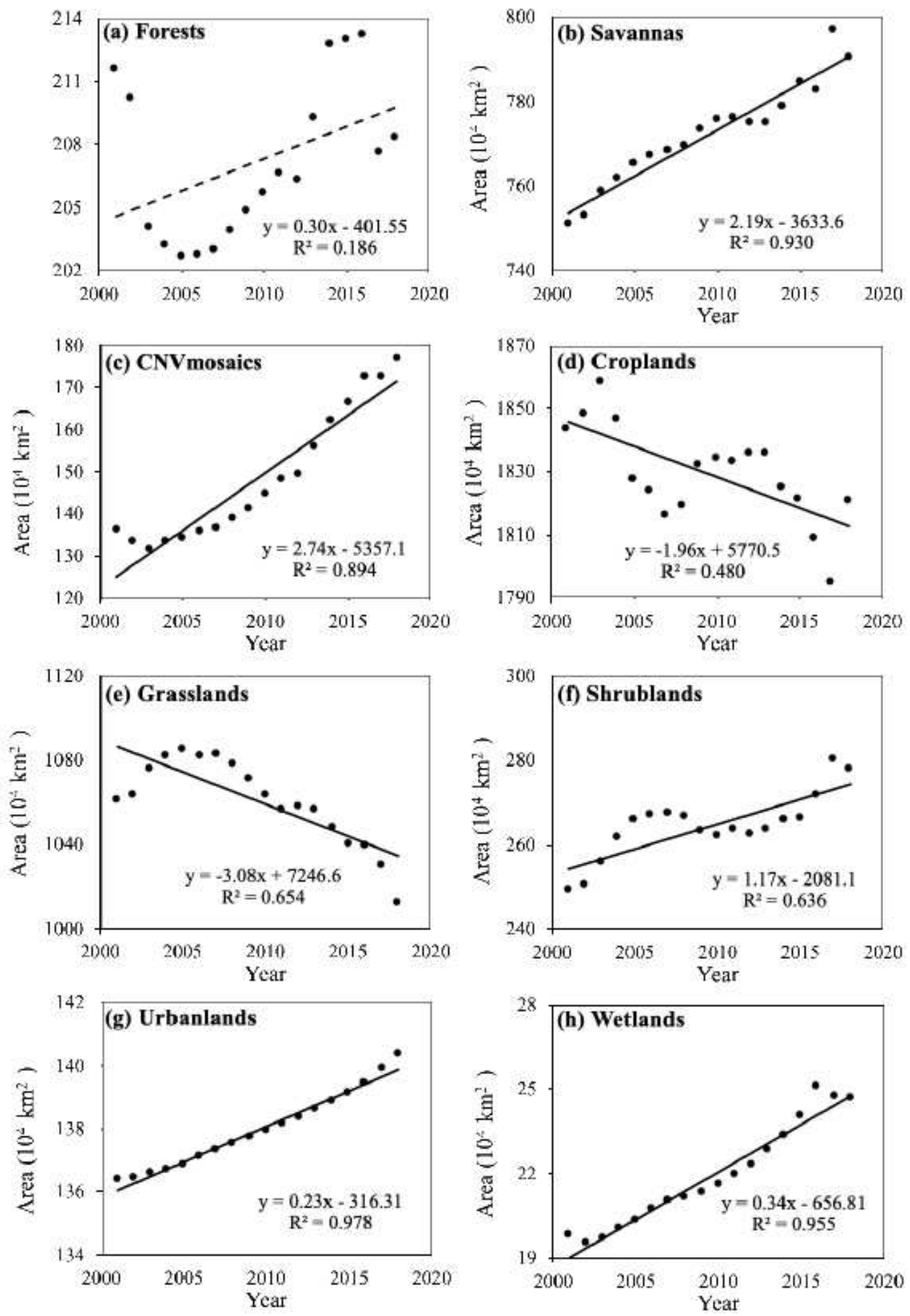

\section{Figure 4}

Total area $(\mathrm{km} 2)$ of eight vegetation types over the period of Jan. 1, 2001-Dec. 31, 2018 in Mediterranean Europe and North Africa (MENA, $20^{\circ} \mathrm{W}-45^{\circ} \mathrm{E} \& 20^{\circ} \mathrm{N}-45^{\circ} \mathrm{N}$ ). 


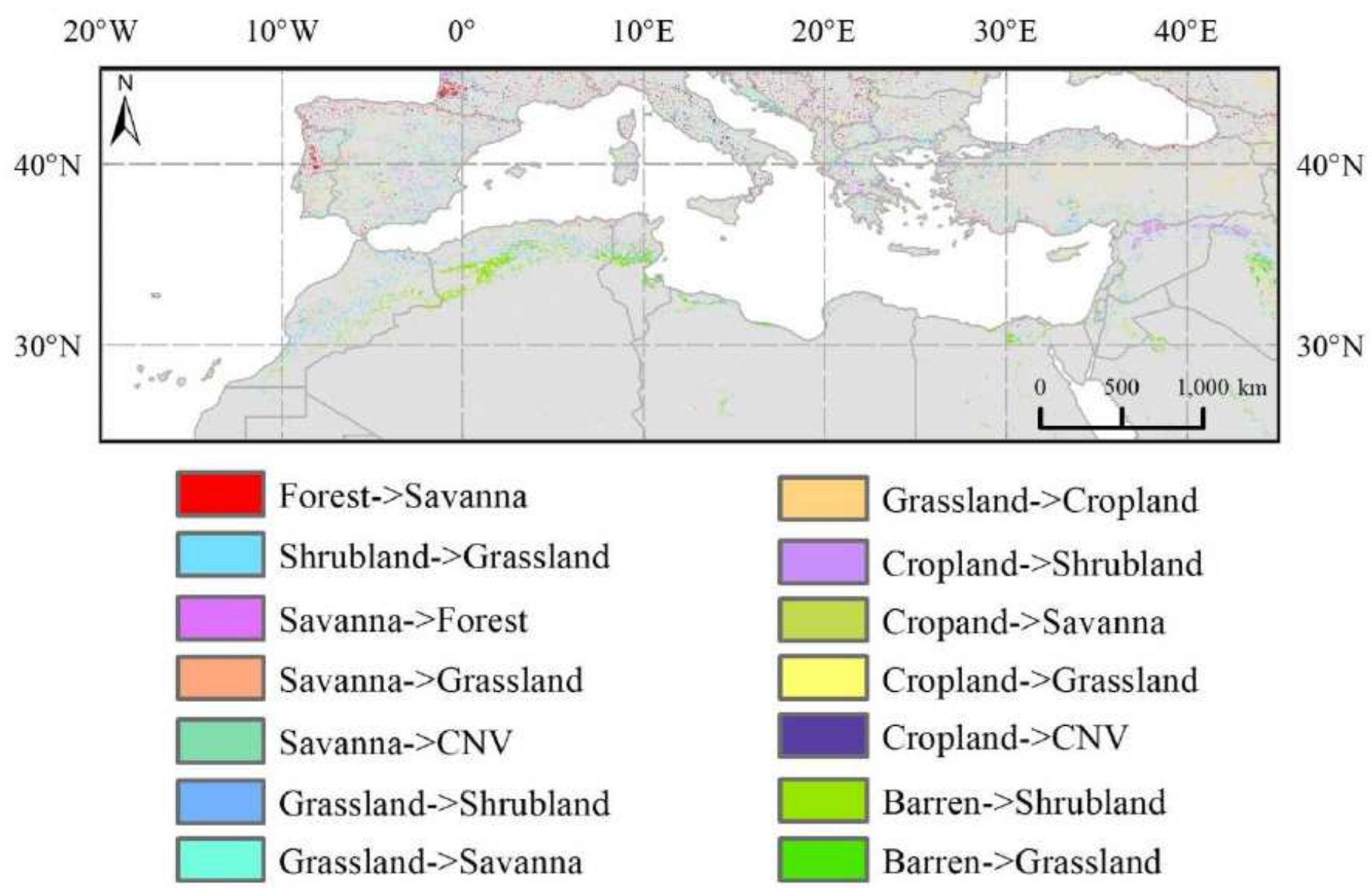

Figure 5

A. map of vegetated areas with changes of landcover types during 2001-2018 (500m resolution) in Mediterranean Europe and North Africa (MENA, $20^{\circ} \mathrm{W}-45^{\circ} \mathrm{E} \& 20^{\circ} \mathrm{N}-45^{\circ} \mathrm{N}$ ). 